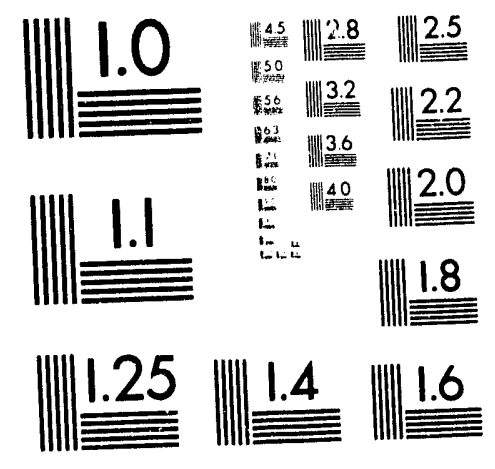



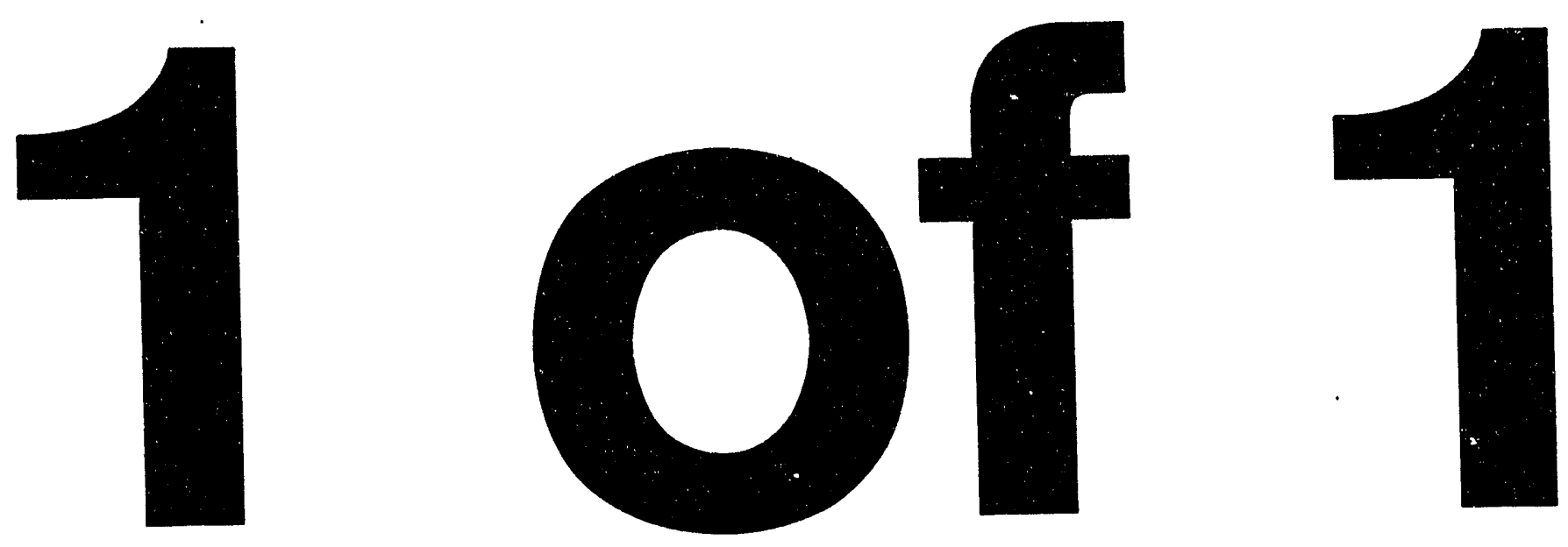


\section{Cost Reduction Study for the LANL KrF Laser-Driven LMF Design}

\section{DISCLAIMER}

This report was prepared as an account of work sponsored by an agency of the United States Government. Neither the United States Government nor any agency thereof, nor any of their employees, makes any warranty, erpress or implied, or assumes any legal liability or responsibility for the accuracy, completer,ess, or usefulness of any information, apparatus, product, or process disclosed, or represents .hat its use would not infringe privately owned rights. Reference herein to any specific cor : ircial product, process, or service by trade name, trademark, manufacturer, or otherwise dres not necessarily constitute or imply its endorsement, recommendation, or favoting by the United States Government or any agency thereof. The views and opinions of authors expressed herein do not necessarily state or reflect those of the United States Government or any agency thereof.

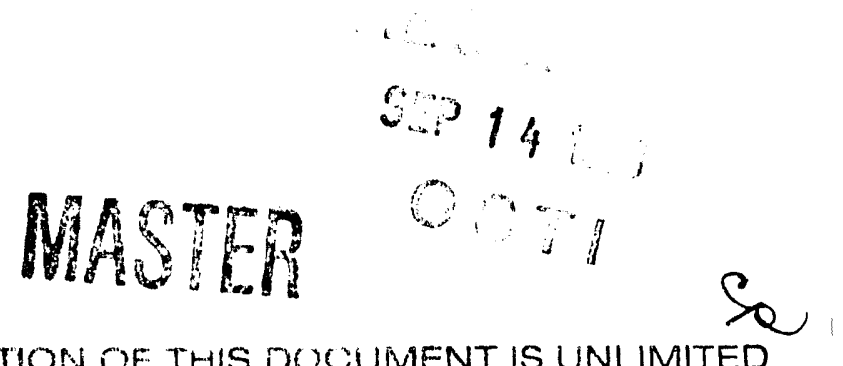




\section{SECTION 1 \\ INTRODUCTION}

\subsection{INTRODUCTION}

This report is in fulfillment of the deliverable requirements for the optical components portion of the LANL KrF Laser-Driven LMF Design Cost Reduction Study. The LLNL tradeoff study was presented during the program mid-term briefing. Cost reduction analysis for electrical components was eliminated by LANL.

This report examines the future cost reductions that may accrue through the use of mass production, innovative manufacturing techniques, and new materials. Results are based on data collection and survey of optical component manufacturers, BDM experience, and existing cost models. These data provide a good representation of current methods and technologies from which future estimates can be made. From these data, a series of scaling relationships were developed to project future costs for a selected set of technologies. The scaling relationships are sensitive to cost driving parameters such as size and surface figure requirements as well as quantity requirements, production rate, materials, and manufacturing processes.

In addition to the scaling relationships, descriptions of the selected processes were developed along with graphical representations of the processes. This report provides a useful tool in projecting the costs of advanced laser concepts at the component level of detail. As a first step, it provides a foundation upon which more detailed study may evolve.

A mix of the most diverse yet comparable technologies was chosen for this study. This yielded a useful, yet manageable number of variables to examine. The study has resulted in a firstorder cost model which predicts the relative cost behavior of optical components within different variable constraints. In general, the study shows that new or innovative technologies such as foam glass lightweighting and large mirror replication may yield substantial cost savings over more traditional technologies - that is, once the significant problems for each technology are solved.

\subsection{REEERENCES}

The following documents were used as primary source materials for development of the analysis methodology. Other data were obtained from vendor supplied literature and responses which are not listed. 
(1). Hoessel, W. C., and L. S. Fields, "Structures Cost Estimating Methodology Volume I," The BDM Corporation, December, 1983.

(2). Hinman, S. F., Eastman Kodak Company, letter to W. Resnik, March 23, 1989.

(3). "High Energy Laser Collimator and Aberration Target Simulator (HELCATS) Cost Analysis," The BDM Corporation, September, 1978.

(4). Taylor, T., Handbook of Electronics Industry Cost Estimating Data, John Wiley \& Sons, 1985.

(5). Hartley, J., EMS at Work, IFS (Publications) Ltd., UK, 1984. 


\section{SECTION 2 \\ OPTICS COST REDUCTION STRATEGIES}

BDM has developed a methodology which weighs program requirements, new technologies and materials, and manufacturing options against associated cost drivers. The general roadmap for this section is depicted in Figure 2.0-1 which shows the cost reduction study

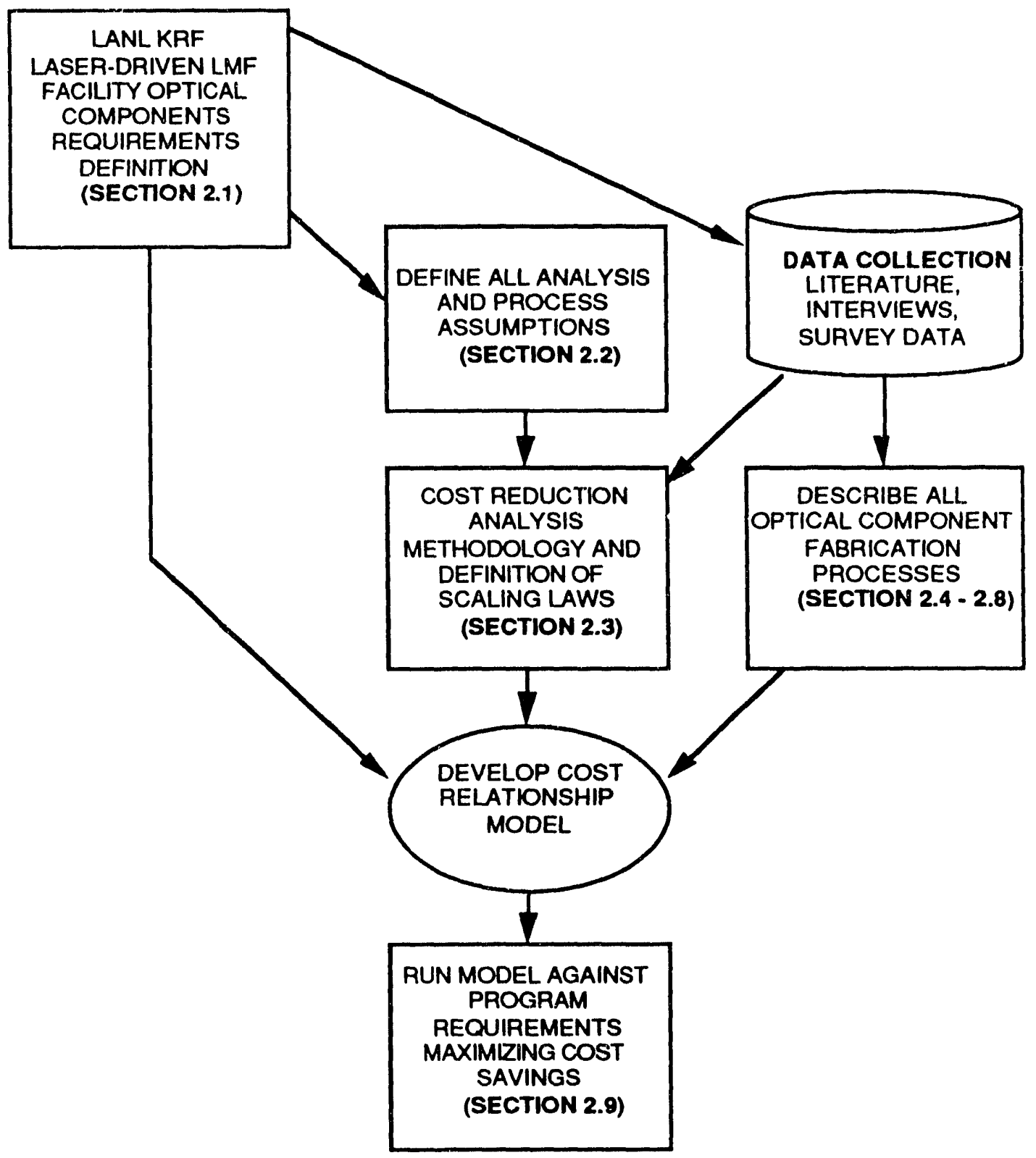

FIGURE 2.0-1. LANL KrF Laser-Driven LMF Facility Optical Components Cost Reduction Study Methodology 
methodology in addition to the flow of this section. LANL'S optical component requirements baselines were developed. Optical component requirements were summarized as four types of mirrors and two types of windows. These baselines were used to define analysis and manufacturing process assumptions and also to constrain and identify data to be collected. Data was collected in the form of literature searches, interviews with component suppliers and vendors, and in a formal survey which was sent to the vendors (a small percentage of vendors surveyed responded). A copy of the survey is provided in the appendix of this document. These data, in addition to BDM experience on similar programs were used to develop cost reduction analysis equations and to define typical manufacturing processes for the components.

In addition to the manufacturing processes, key cost drivers and considerations were identified along with design impacts of different process alternatives. The manufacturing process definitions and analysis formulae and scaling laws were key inputs in development of a cost relationship model. This model shows the relative cost impact of variance of mirror design parameters such as materials, technologies, geometries, and manufacturing methods. The model is a Microsoft EXCEL spreadsheet developed on an Apple Macintosh computer. The model has been run under the most cost effective design parameters (least expensive materials, automation, etc.) for the four types of baseline mirror components to provide a simple sensitivity analysis. The model is provided on disk to allow the reader to perform a more detailed sensitivity analysis. 


\subsection{OPTICS REOUIREMENTS}

This analysis is based on optics requirements defined in the LANL report titled "KrF Laser-Driven LMF Design - Interim Report -". The quantities of optics are summarized below in Table 2.1-1, Major Optical Compontnt Quantities. These quantities are characterized for the analysis as being 6 major types of optics. They are:

(1) Rectangular Sphere Mirror - 2070

(2) Round Sphere Mirror - 3600

(3) Rectangular Plano Mirror - 2280

(4) Round Plano Mirror - 900

(5) Rectangular Pyrex Window - 270

(6) Round Py:ex Window - 900

\begin{tabular}{|r|c|}
\hline 64.9 CM X 129.7 CM RECTANGULAR WINDOW & 270 \\
\hline 87 CM ROUND WINDOW & 900 \\
\hline 55.4 CM X 67.1 CM RECTANGULAR WEAKLY POWERED SPHERE & 900 \\
\hline 90 CM ROUND WEAKLY POWERED SPHERE & 3600 \\
\hline 199.9 CM X 419.8 CM RECTANGULAR PLANO & 30 \\
\hline 54.9 CM X 129.7 CM RECTANGULAR WEAKLY POWERED SPHERE & 270 \\
\hline 55.8 CM X 94.8 CM RECTANGULAR LIGHTWEIGHT PLANO & 900 \\
\hline 95 CM ROUND LIGHTWEIGHT PLANO & 900 \\
\hline
\end{tabular}

TABLE 2.1-1 Major Optical Component Quantities 
The damage threshold assumed for the analysis was held to $5 \mathrm{~J} / \mathrm{CM}^{2}$ or better at $248 \mathrm{~nm}, 20$ ns. The optical surface properties were specified as a surface error of $\lambda / 10$ and $20 \AA$ RMS roughness. 


\subsection{COST ANALYSIS ASSUMPTIONS}

A number of assumptions were specified in order to keep the analysis within manageable limits. The general purpose assumptions (applicable to more than one hardware item) are described in this paragraph. Detailed assumptions specific to a particular scaling relationship are contained in the discussion of each individual relationship.

(1) All costs are in fiscal year 1990 (FY90) dollars.

(2) The costs are f.o.b. the supplier. Costs for transportation to the LMF site, attrition during transportation, and installation and material pass through costs by an LMF integrating contractor are excluded. The costs of vendor support during construction are also excluded.

(3) The costs are a composite of the experience of several companies.

(4) The costs for materials/purchased parts, fabrication labor, test/inspect labor, and handling are estimated in terms of average costs for a given production quantity. Total costs for a given program quantity can be obtained by multiplying average cost by the total quantity. The average cost does not equal the unit cost or the cost of the last unit produced. We have used asymptotic learning curve theory which assumes that production quantities are sufficiently large that the average cost and unit cost curves are parallel on log-log paper. For most learning curve slopes, the asymptotic assumption is quite accurate when the quantities involved are greater than about 100 units.

(5) In cases where vendor data were quoted in terms of manhours rather than dollars, we used a base labor rate of $\$ 15 /$ hour (FY90) factory average, an overhead of 150 percent, and a 25 percent factor to cover general and administrative (G\&A) and fee. This gives a burdened labor rate of $\$ 46.9$ /hour. Improved processes and competition effects may reduce the overhead factors in the future and lower costs may be realized beyond the projections in this report.

In addition to the analysis constraints applied above, assumptions were made on certain parameters and quantities to provide a "baseline" by which suppliers could more readily provide data for the analysis. These assumptions were as follows: 
(1) A "typical" rectangular mirror dimension is 26 " by 26 " square ( $66 \mathrm{~cm} \times 66$ $\mathrm{cm})$

(2) A "typical" round mirror is 37 " diameter $(94 \mathrm{~cm})$

(3) A weakly powered spherical convex or concave mirror will have a radius of curvaiure of 25 meters

(4) Solid glass mirror thickness is $1 / 5$ the rectangle diagonal measurement or round diameter

(5) All windows were assumed to be constructed of solid Pyrex glass. 


\subsection{COST REDUCTION ANALYSIS METHODOLOGY}

\subsubsection{INTRODUCTION}

This section presents the cost scaling laws developed during this study. These laws were derived through discussions with optics vendors, review of existing cost models, analysis of BDM data, and from experience with analogous manufacturing processes. The major paragraphs of this section address mirror blanks, mirror figuring/polishing, coatings, windows, mounts, and replication. Within each of these major paragraphs, subparagraphs are developed for the cost elements of raw materials/purchased parts, fabrication labor, test/inspect labor, handling labor, and non-recurring tooling/equipment. Such a subdivision was necessary to capture the impact of the many possible technologies being considered in this study. Some technologies may reduce one cost element, but increase anot...r. Separating costs into these discrete elements provided a firstorder means for assessing the magnitucies of the various cost impacts. Finer categorizations are possible (e.g., fabrication labor could be divided into manufacturing engineering, production control, engineering liaison, touch labor, etc.). At this time such a subdivision would not necessarily improve the results given the basic uncertainties in the available data and the extrapolation methods.

Each major optical component type (windows and mirrors) has been analyzed. The first step was to identify for each component the major fabrication steps. The steps are as follows:

(1) Plano and spherical mirrors
(a) Blank Fabrication
(b) Surface polishing/figuring
(c) Coating
(d) Mounting

(2) Windows
(a) Blank Fabrication
(b) Surface polishing/figuring
(c) Coating
(d) Mounting

Next, for each of these fabrication steps, the fabrication process was defined from a combination of current literature, interviews, and survey data collected during this study. Each of 
the fabrication processes represents a generic summary of the actual types of processes in use today. The exception is the fabrication process for foamed glass mirror blanks. Since there is no current supplier of foamed glass mirror blanks, a process was devised from currert methods for manufacturing foamed glass and fusing lightweighted materials to glass front and back plates. Cost reduction methods for each fabrication process (such as automation, new manufacturing processes, etc.) have been identified in the descriptive text for each process.

Cost driving parameters were identified for manufacturing, raw material costs, equipment costs, testing, and material handling. These cost drivers were then used to develop characteristic equations that provide a quantity-of-one cost. The costs are catagorized into recurring and nonrecurring portions. For each fabrication process step, an estimate is made for each cost driver (such as time and labor estirnates). The model is fed these data for each optical component type (such as geometry, size, plano or spherical, etc.) resulting in an estimated first unit cost and associated non-recurring cost. The recurring portion of the quantity-of-one cost was then extended with learning curves to estimate quantity discounts based on a learning rate for each process.

Finally, the model was used to estimate costs of the quantities of optical components specified in table 2.1-1. These costs are summarized in paragraph 2.8 of this report.

\subsubsection{SCALING RELATIONSHIPS}

This section has six major subsections corresponding to cost scaling laws for mirror blanks, mirror figuring/polishing, mirror coating, windows, mounts, and replication.

\subsubsection{Mirror Blank}

Mirror blank costs are divided into recurring and non-recurring costs. The recurring costs include raw materials/purchased parts, fabrication labor, test/inspect labor, and handling. These costs recur with the number of units produced. The non-recurring costs include the purchase of furnaces, molds, tools/jigs/fixtures, and test equipment. These are investment items that relate more to production rates than to total units produced. The costs to maintain equipment and tools is part of the factory overhead factor and is therefore included in recurring costs.

(1) Raw Materials and Purchased Parts - The raw materials cost is estimated with the following relationship:

(Blank weight in pounds) (material factor) (geometry factor)(curvature factor) (quantity) (..074 $^{-026}$ 
In this relationship the blank weight is the final weight of the part. It is an input bared on measurements or computed from volume and material density. T ae material factor is obtained from Table 2.3.2.1-1 and includes the cost for scrap, material burden (purchasing, inventory control etc.), transportation to the vendor, G\&A, and fee as well as the raw price of material in the frial product.

TABLE 2.3.2.1-1. BLANK MATERIAL FACTORS

(\$ per pound)

$\begin{array}{ll}\text { Zerodur } & 19 \\ \text { Borosilicate HEXTEK } & 24 \\ \text { Solid Glass or Foam Glass } & 5 \\ \text { Aluminum } & 4 \\ \text { Copper } & 3 \\ \text { Silicon Carbide } & 30 \\ \text { Beryllium } & 48\end{array}$

Data in the table were obtained from discussions with suppliers and BDM files and experience.

The Curvature Factor $=\quad 1.00$, if Plano HEXTEK

1.25, if Concave Sphere HEXTEK

1.63, if Convex Sphere HEXTEK

1.00 , all others.

This factor was derived from a limited amount of HEXTEK data and should be investigated further for other technologies and materials.

The term: $\frac{\text { (quantity) }}{. .074}$ corresponds to a 95 percent material discount curve, where quantity refers to the cumulative number of units produced. A 95 percent curve is typical in our experience for material discounts.

The geometry factor $=\quad$ i.ô, if recianigüläi IFXTEK 


\section{2, if circular HEXTEK \\ 1.0 , all others}

The geometry factors were based on survey data supplied by HEXTEK, and the assumption that geometry has limited effect for other materials.

(2) Eabrication Labor - The fabrication labor cost includes factory touch labor, manufacturing engineering, production control and similar activities. The labor includes both foundry and machine shop personnel. For metallic mirrors it was assumed that investment mold castings would result in a near net shape and some machining would be needed to produce net shape.

The fabrication relationship is:

(Blank weight in pounds) (material factor) (curvature factor) (geometry) (Quantity)-.152 .848

The material factor $=$

$\begin{array}{ll}\$ 12 / \mathrm{b} & \text { Solid Glass } \\ \$ 115 / \mathrm{lb} & \text { Foam Glass } \\ \$ 78 / \mathrm{lb} & \text { HEXTEK } \\ \$ 30 / \mathrm{lb} & \text { Aluminum } \\ \$ 28 / \mathrm{lb} & \text { Copper } \\ \$ 120 / \mathrm{lb} & \text { Silicon Carbide } \\ \$ 180 / \mathrm{lb} & \text { Beryllium }\end{array}$

The data are based on survey results and the data from the BDM structures cost model (reference 1).

The curvature factor $=$

1.00, if Plano HEXTEK

1.25 , if Concave Sphere HEXTEK

1.63, if Convex Sphere HEXTEK

1.0 , all other materials.

This factor was derived from HEXTEK data.

The geometry factor $=$ 1.0, if rectangular HEXTEK 


\section{2 , if round HEXTEK \\ 1.0 , all others.}

The geometry factor was derived from data supplied by HEXTEK. The other materials/technologies are expected to be less sensitive to geometry and curvature at the blank fabrication step. The quantity term assumes a 90 percent learning curve on labor.

(3) Test/Inspect Labor - The estimating relationship is:

(Blank weight in pounds)(test/inspect factor) (curvature factor)(geometry factor) $\frac{\text { (quantity) }}{.152}$

The test/inspect factor is from Table 2.3.2.1-2

\section{TABLE 2.3.2.1-2. TEST/INSPECT FACTOR}

(\$ per pound)

$\begin{array}{ll}\$ 1.0 & \text { Solid glass } \\ \$ 8.0 & \text { HEXTEK, Foam glass } \\ \$ 3.0 & \text { Aluminum } \\ \$ 3.0 & \text { Copper } \\ \$ 12.0 & \text { Silicon Carbide } \\ \$ 18.0 & \text { Beryllium }\end{array}$

This factor was estimated as 10 percent of fabrication labor based on survey data and BDM experience with similar manufacturing processes. The other terms in the relationship are as defined for fabrication labor.

(4) Handling Labor - The relationship for estimating handling labor is:

(Blank weight in pounds) (handling factor) (curvature factor)(geometry) (quantity)-. 152 .848

The handling factors are found in Table 2.3.2.1-3.

TABLE 2.3.2.1-3. HANDLING FACTORS

(\$ per pound)

.0 Solid Glass 


$\begin{array}{ll}\text { 8.0 } & \text { HEXTEK and Foam glass } \\ 3.0 & \text { Aluminum } \\ 3.0 & \text { Copper } \\ 12.0 & \text { Silicon Carbide } \\ 18.0 & \text { Beryllium }\end{array}$

The handling factor was derived from BDM experience. Handling is a function of the number of steps in the blank fabrication process. The other terms are as defined for fabrication labor.

(5) Tooling/Equipment - The non-recurring costs include the purchase and installation of furnaces and the design and fabrication of molds. It is assumed that no existing furnaces and tools would be inherited for the LMF program. Furnace lifetime has been assumed to be greater than program duration in the estimating relationship. Construction costs for dedicated buildings or remodeling existing buildings are excluded from this cost element. The furnace relationship is:

(Program Quantity Requirement)/(Program Schedule in Months)/(Units/month factor)x furnace cost]

The units per month factor is from Table 2.3.2.1-4.

TABLE 2.3.2.1-4. UNITS PER MONTH FACTOR

$\begin{array}{ll}15 & \text { Solid glass } \\ 7 & \text { HEXTEK } \\ 50 & \text { Metal } \\ 10 & \text { Foam glass }\end{array}$

These factors assume 4 blanks can be simultaneously processed per furnace, which HEXTEK indicated was true for the mirror sizes assumed in this study. The $\$ 50,000$ per furnace factor was supplied by HEXTEK. A value of $\$ 100,000$ per furnace is used for suppliers other than HEXTEK assuming they would contract out the work.

The non-recurring cost to design and manufacture molds is roughly estimated with the relationship:

(blank weight in pounds) $\cdot{ }^{71}(\$ 2440 / \mathrm{b})$ (number of molds) 
This relationship is based on data for investment mold metallic castings (reference 1). The number of molds is a function of program schedule and processing time. This can be approximated as:

(Program Quantity Requirement)/(Program Schedule in Months)(mold factor)

Where mold factor $=.5$ for foam glass

.33 for solid glass or HEXTEK

.1 for metal mirror and replicated

\subsubsection{Mirror_Blank_Figuring/Polishing}

Separate relations are provided in each recurring cost element to account for mirror curvature (e.g., plano, concave sphere or convex sphere). As indicated earlier, these relations assumed that the surface roughness requirement was $20 \AA$ root mean square.

(1) Materials - The materials consumed in figuring/polishing plano mirrors are estimated with the relationship:

$(\mathrm{MFF})(\$ 220)(\mathrm{D} / 31)^{1.15}(\mathrm{~K} 1)$ (Quantity)
.848

$\mathrm{D}=$ mirror diameter in inches if round, and diagonal length in inches if rectangular.

$\mathrm{K} 1=1$, if conventional figuring methods .85 , if ion figuring.

Material Figuring Factor (MFF) $=1.0$, glass, Aluminum, Copper

\section{6, Silicon Carbide}

2.0, Beryllium

For concave spherical mirrors the relationship is:

$$
\begin{gathered}
(\mathrm{MFF})(\$ 996)(\mathrm{D} / 31)^{1.15}\left(\mathrm{~K}_{2}\right) \text { (Quantity) } \\
.848
\end{gathered}
$$

where $\mathrm{D}$ is as defined above, and $\mathrm{K}_{2}=\quad 1.0$, if conventional

.52 , if ion figuring

For convex spherical mirrors the relationship is: 


$$
(\mathrm{MFF})(\$ 1256)(\mathrm{D} / 31)^{1.15}\left(\mathrm{~K}_{3}\right) \frac{(\text { Quantity) }}{. .152}
$$

where $\mathrm{K}_{3}=1.0$ if conventional

.57 if ion figuring.

These relationships were estimated assuming materials consumption costs to be 5 percent of fabrication labor cost (reference 1). Labor costs were assumed to follow a 90 percent learning curve so materials were assumed to as well.

(2) Eabrication Labor - For plano mirrors the relationship is:

$(\mathrm{MFF})(\$ 4330)(\mathrm{D} / 31)^{1.15}\left(\mathrm{~K}_{1}\right)$ (Quantity) $)^{-152}$ .848

where $\mathrm{D}$ is the diameter in inches if circular and the diagonal length in inches if square. The 1.15 exponent was empirically derived for the BEECEE laser cost model (reference 3).

$$
\begin{array}{r}
\mathrm{K}_{1}=\quad 1.0, \text { if conventional } \\
.85, \text { if ion figuring. }
\end{array}
$$

The relationship was based in part on Kodak data (reference 2). Kodak indicated a much more modest effect of production quantity on cost than the relationship predicts. However, we believe a 90 percent learning curve is more representative of the cost quantity relationship that would be experienced. This type of learning curve accounts for process improvements that cccur over time and tends to be the largest determinant of cost reduction. Kodak indicated in our discussions that large production quantity costs could be reduced if they overpolish and randomly inspect.

For concave spherical mirrors the relationship is:

$$
\begin{aligned}
& (\mathrm{M} \cdot \mathrm{F})(\$ 19900)(\mathrm{D} / 31)^{1.15} \underset{\left(\mathrm{K}_{2}\right)}{.848}(\text { (Ouantity) })^{-.152} \\
& \mathrm{~K}_{2}=1.0 \text { if conventional }
\end{aligned}
$$


.52 if ion figuring.

For convex spherical mirrors the relationship is:

$$
\left.\begin{array}{l}
(\mathrm{MFF})(\$ 25127)(\mathrm{D} / 31)^{1.15}\left(\mathrm{~K}_{3}\right)(\text { Quantity }) \\
\mathrm{K} 3=1548
\end{array}\right) \begin{aligned}
& 1.0 \text { if conventional } \\
& .52 \text { if ion figuring. }
\end{aligned}
$$

(3) Test/Inspect Labor - The relationship for plano mirrors is:

$$
\begin{aligned}
& \left.(\mathrm{MFF})(\$ 1300)(\mathrm{D} / 31)^{1.15}\left(\mathrm{~K}_{1}\right) \text { (Quantity) }\right)^{-.152} \\
& \mathrm{~K}_{1}=\begin{array}{c}
1.00, \text { if conventional } \\
.85, \text { if ion figuring. }
\end{array}
\end{aligned}
$$

For concave spherical mirrors the relationship is:

$$
\left.\begin{array}{l}
(\mathrm{MFF})(\$ 5956)(\mathrm{D} / 31)^{1.15}\left(\mathrm{~K}_{2}\right)(\text { Quantity })^{-.152} \\
.848
\end{array}\right) \begin{aligned}
& 1.0, \text { if conventional } \\
& .52, \text { if ion figuring. }
\end{aligned}
$$

For convex spherical mirrors the relationship is:

$$
\begin{aligned}
& (\mathrm{MFF})(\$ 7540)(\mathrm{D} / 31)^{1.15}\left(\mathrm{~K}_{3}\right)(\mathrm{Quantity})-.152 \\
& \mathrm{~K} 3=\mathbf{8 4 8} \\
& \begin{array}{l}
1.0, \text { if conventional } \\
.52, \text { if ion figuring. }
\end{array}
\end{aligned}
$$

These relationships were estimated from survey data supplied by Kodak (reference 2), and the assumption that test/inspect labor is 30 percent of fabrication labor for the figuring/polishing process (reference 4).

(4) Handling Labor - For plano mirrors the relationship for handling labor is:

$(\mathrm{MFF})(\$ 430)(\mathrm{D} / 31)^{1.15}\left(\mathrm{~K}_{1}\right)$ (Ouantity) $^{-.152}$ 
In this relationship $D$ is the mirror diameter in inches if circular and the diagonal in inches if rectangular.

$\mathrm{K}_{1}=1.00$, if conventional

.85 , if ion figuring.

For concave spherical mirrors the relationship is:

$(M F F)(\$ 1990)(D / 31)^{1.15}\left(K_{2}\right)$ (Quantity) $)^{-152}$

$\mathrm{K}_{2}=1.00$, if conventional

.52 , if ion figuring.

The relationship for convex spherical mirrors is:

$$
\begin{array}{ll}
(\mathrm{MFF})(\$ 2513)(\mathrm{D} / 31)^{1.15}\left(\mathrm{~K}_{3}\right)\left(\text { Quantify }^{-1.152}\right. & .848 \\
\mathrm{~K} 3=\mathbf{1 . 0 , \text { if conventional }} \\
.57, \text { if ion figuring. }
\end{array}
$$

(5) Tooling and Equipment - The non-recurring cost for fixtures is estimated with the expression:

$$
\text { (mirror weight in pounds) (\$45/pound) (material factor)(R).3 }
$$

The material factor $=1.0$, for solid glass

$$
\begin{aligned}
& \text { 4.0, for HEXTEK or Foam glass } \\
& 1.0 \text {, for } \mathrm{Al}, \mathrm{Cu}, \mathrm{SiC} \\
& 1.5 \text {, for } \mathrm{Be} \text {. }
\end{aligned}
$$

The variable, $R$, is the planned peak production rate in units per month. This relationship was taken from reference 1 . For initial estimates, $R$ can be approximated by the average production rate for the program.

The cost for planetary polishers is estimated as: 


$\frac{\text { Prooram Quantity }}{\text { Program Schedule in Months }} \times \frac{1}{16 \text { units/mo }} \times \quad \$ 2500000 /$ machine

The 16 units per month is the current experience assuming 3 units are being polished simultaneously. The $\$ 2,500,000$ per machine is based on discussions with Zygo personnel. The number of polishers should be rounded to an integer value. The relationship is currently insensitive to whether the mirrors are planar or spherical.

The cost for ion figuring equipment is:

(Program Quantity)/(program schedule)/(20 units/month)( $\$ 3,000,000$ per machine)

The cost for aspherizing machines is:

(Frogram Quantity)/(program schedule)/(5 units/month)(\$3,000,000 per machine)

The units per month data are approximate values for the nominal mirror characteristics assumed in this study. The machine costs were based on discussions with Kodak and by analogy to similar equipment.

\subsubsection{Mirror Coating}

The recurring cost for mirror coating is the sum of the costs for materials, factory labor, test/inspect labor, and handling labor. The non-recurring costs are for equipment design, fabrication and installation.

(1) Materials - Coating materials costs are projected with the relationship:

$(\$ .9)(D)^{2.4} \frac{(\text { Quantity })}{. .152}$

In the relationship $\mathrm{D}$ is $\mathrm{se}$ mirror diameter in inches for circular mirrors and the diagonal length in inches for rectangular mirrors. The quantity term is the cumulative number of mirrors produced.

This relationship was derived from data supplied by OCLI. The OCLI data were divided into materials, labor, test/inspect and handling with BDM experience factors. The relationship is applicable for diameters between 10 and 80 inches. Caution should be exercised for extrapolations beyond this range of diameters. 
(2) Eactory Labor - The relationship for factory labor is:

(F) $(D)^{2.4} \frac{(\text { Quantity })}{. .152}$

where $\mathrm{F}=\$ 2.0$ for solid glass

$\$ 1.8$ for light weight glass

$\$ 2.0$ all other materials.

Extrapolation for diameters outside of the range from 10 to 80 inches are not advised.

(3) Test/Inspect Labor - The test/inspect relationship is:

(T) $(D)^{2.4} \frac{\text { (Quantity) }}{. .152}$

where $\mathrm{T}=\$ .6$, if solid glass

$\$ .5$, if light weight glass

$\$ .6$ all other materials.

(4) Handling Labor - The handling relationship is:

(H) $(D)^{2.4} \frac{(\text { Quantity })}{. .152}$

where $\mathrm{H}=\quad \$ .2$ if solid glass

$\$ .1$ if light weight glass

$\$ .2$ all other materials.

(5) Tooling and Equipment - The non-recurring cost for the design, fabrication and installation of equipment and tooling is estimated with the relationship:

$$
\begin{aligned}
& \$ 690(D)^{1.35} \text {, if } 10 \leq D \leq 40 \text { inches } \\
& \$ .119(D)^{3.7} \text {, if } 40 \leq D \leq 80 \text { inches. }
\end{aligned}
$$

This relationship was developed by simple curve fitting to OCLI data. 


\subsubsection{Windows}

The window cost is divided into blank, figuring/polishing, and coating. Each of these is, in turn, subdivided into raw materials, fabrication labor, test/inspect labor, handling labor, and non-recurring costs. All windows were assumed to be constructed of solid Pyrex glass. The model does not provide calculations for windows at this time, however, these equations could be easily added to the model at a later time.

(1) Blank - The raw materials cost for the window blank is estimated as:

$$
\text { (Blank we ght in pounds) (\$5//b) (Quantity) })^{-.074}
$$

The quantity term refers to the cumulative number of units to be produced. The weight is an input that is estimated from window dimensions and the density of Pyrex. The relationship includes losses for scrap, material burden, G\&A and fee as well as the raw material price.

Fabrication labor is estimated as:

$$
\text { (Blank weight in pounds) (\$12/b) } \frac{(\text { Quantity })^{-.152}}{.848}
$$

This relationship assumes a 90 percent learning rate on labor.

The test/inspect labor is estimated as:

$$
\text { (Blank weight in pounds) (\$1//b) } \frac{(\text { Quantity) }}{.848}
$$

The handling cost is:

(Blank weight in pounds) $(\$ 1 / \mathrm{lb}) \frac{(\text { Quantity) }}{. .152}$

The non-recurring cost of furnaces is:

(program quantity)/(program schedule)/15)(\$100,000 per furnace)

This relationship assumes four blanks are heated simultaneously. The cost to design and construct molds is: 
(window weight in lbs). ${ }^{71}(\$ 2440 / \mathrm{b})$ (program quantity)/(program schedule)(.33)

(2) Eiguring/Polishing - The materials consumed in polishing windows are estimated as:

$$
\left.(\$ 440)(D / 31)^{1.15} \text { (SF) (K)(Quantity) }\right)^{-.152}
$$

In this relationship SF is a function of surface figure requirements. Values of SF can be obtained from figure 2.3.2.4-1. D is the diameter in inches if the window is circular and the diagonal in inches if it is rectangular.

$\mathrm{K}=1.0$, if conventional methods

.85 , if ion figuring.

The factory labor is estimated as:

$$
(\$ 8660)(D / 31)^{1.15}(\mathrm{SF})(\mathrm{K}) \frac{(\text { Quantity) }}{. .152}
$$

$\mathrm{D}$ is as above and SF can be read from figure 1.

$\mathrm{K}=1.00$, if conventional methods

.85 , if ion figuring.

Test/inspect labor is estimated as:

$$
\left.(\$ 2600)(D / 31)^{1.15}(S F)(K) \text { (Quantity) }\right)^{-.152}
$$

SF is an adjustment for surface figure from figure 2.3.2.4-1 and $\mathrm{K}$ is as defined above. A value of .5 at $x=0$ is meaningless and should be ignored.

Handling labor is estimated with the relationship:

$$
(\$ 860)(D / 31)^{1.15}(\mathrm{SF})(\mathrm{K}) \text { (Quantity) }^{-.152}
$$

In the relationship $\mathrm{D}, \mathrm{K}$, and $\mathrm{SF}$ are as defined for fabrication labor. 


\section{SURFACE FIGURE}

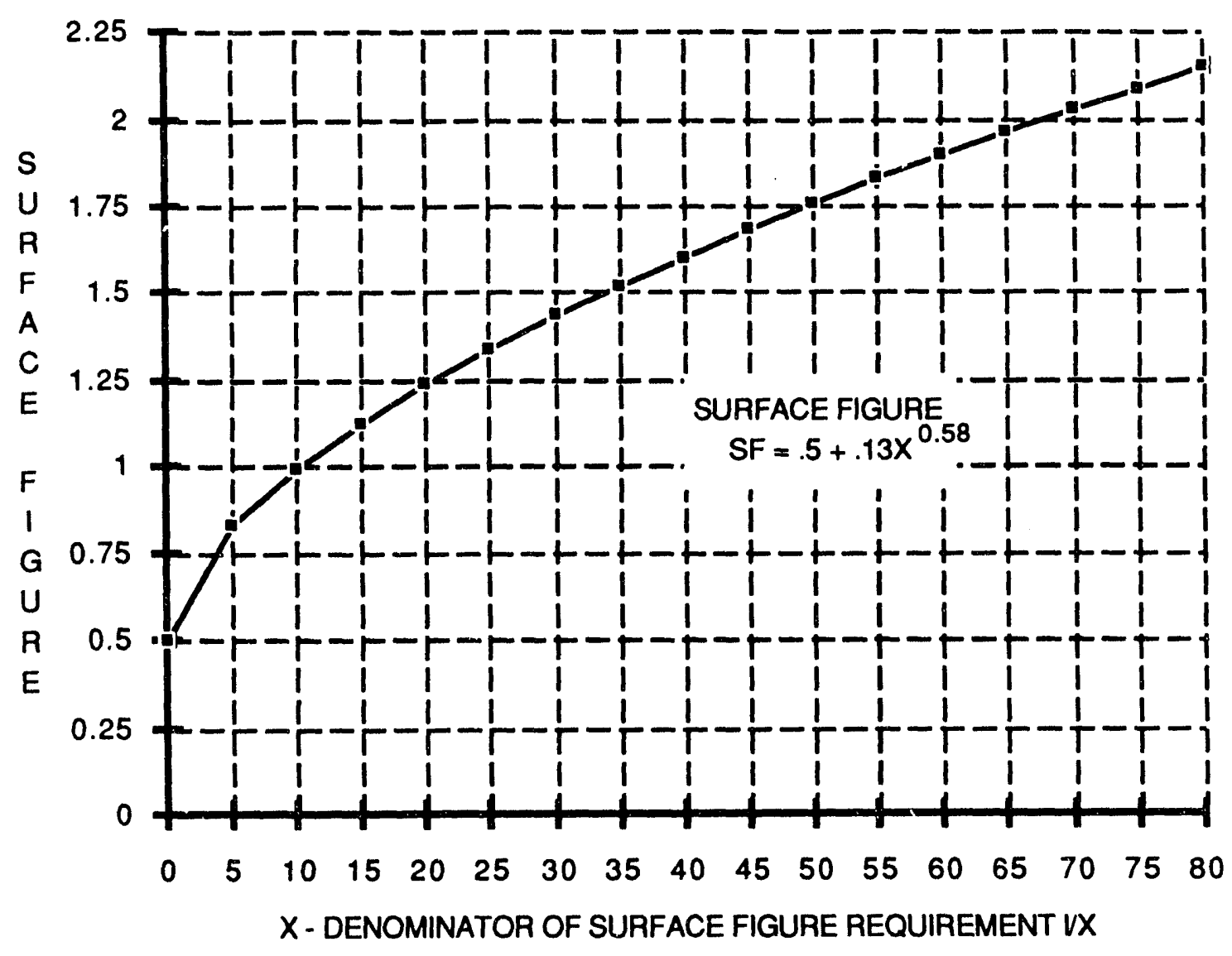

FIGURE 2.3.2.4-1 Surface Figure (SF) as a Function of Surface Requirements

The non-recurring cost for fixtures is estimated with the expression: (window weight in pounds) (\$45/lb) R.3. In this expression, $R$ is the planned peak production in windows per month.

The cost for planetary polishers is:

$\frac{\text { Proaram Quantity }}{\text { Program Schedule in Months }} \times \frac{1}{\text { units/month }} \times \$ 2,500,000$


The units/month factor depends on size of the window and the suriace roughness requirement. For a window with $D=31$ inches and $20 \AA$ surface roughness, 3 windows will fit on current generation polishers and about 8 units can be produced per month assuming polishing of both sides.

(3) Window Coating - The coating materials cost is estimated as:

$$
(\$ 1.8)\left(D^{2.4}\right) \frac{(\text { Quantity) }}{. .152}
$$

$D$ is as above, and quantity is the cumulative number of windows to be produced. The relationship was derived from OCLI data and is applicable to windows for which $10 \leq \mathrm{D} \leq 80$ inches. It was assumed that both sides would require coating.

The factory labor cost is:

$$
(\$ 4.0)(D)^{2.4} \frac{\text { (Quantity) }^{-.152}}{.848}
$$

The test/inspect labor cost is:

$$
(\$ 1.2)(D)^{2.4} \frac{(\text { Quantity })}{.848}
$$

The handling labor cost is:

$$
(\$ .4)(D)^{2.4} \frac{(\text { Quantity })}{. .152}
$$

The non-recurring cost for tools and equipment associated with coating is estimated as:

$$
\begin{aligned}
& (\$ 690) D^{1.35} \text {, if } 10 \leq D \leq 40 \text { inches } \\
& \text { or } \\
& (\$ .119) D^{3.7} \text {, if } 40 \leq D \leq 80 \text { inches }
\end{aligned}
$$

This relationship was developed by fitting OCLI data. 
(4) Mounting costs will be comparable for non-motorized mirrors of similar dimension.

\subsubsection{Mounts}

The cost for mounts is based on the weight of the mount and whether it is fixed or movable. In the absence, of hetter data, the weight of the mount can be roughly estimated as 1.3 imes the weight of the window or mirror if the mount is fixed and 1.6 times if movable. These factors were empirically derived from a limited set of AFWL program data (Reference 3).

(1) Raw Materials and Purchased Parss - For fixed mounts the materials are estimated as:

(mount weight in pounds) (geometry) (\$15.50/pound) $\frac{(\text { Quantity })}{.926}$

where geometry $=1$, if circular (round) mirror

9 , if rectangular.

Quantity is the cumulative number of mounts to be produced.

For motorized mounts the relationship is:

$$
\text { (molnt weight in pounds) (geometry) }\left(\$ 31.75 / \text { pound) } \frac{(\text { Quantity) }}{.926}\right.
$$

These relationships were derived from data in reference 3 , assuming that materials are 25 percent of the total cost for a mount at unit 1 . Materials were assumed to follow a 95 percent learning curve; which is representative of BDM experience.

(2) Eabrication Labor - The fabrication labor for fixed mounts is:

(mount weight in pounds)(geometry)(manufacturing factor)(\$40/b)(Quantity) $)^{-152}$

The geometry factor is as above and the manufacturing factor:

$$
\begin{gathered}
=\quad 1.0 \text {, if traditional methods } \\
.7, \text { if automated FMS }
\end{gathered}
$$

For movable mounts the relationship is: 
(mount weight in pounds) (geometry) (manufacturing factor)(\$81/pound) $\frac{\text { (Quantity) }}{.848}$ The fabrication labor follows a 90 percent learning curve. The Flexible Manufacturing System (FMS) factor was derived from BDM experience and data in reference 5 .

(3) Test/Inspect Labor - The estimating relationship is:

(mourit weight in pounds) (geometry) (manufacturing factor)(test factor) (Quantity) -.152 $^{-1548}$

Geometry and manufacturing factors are as defined above. The test factor is from Table 2.3.2.5 - 1 .

TABLE 2.3.2.5 - 1. TEST FACTORS

(\$/pound)

Visual Inspect Visual and Vibration

Fixed

4

6

Movable

8

12

The factors in Table 2.3.2.5 - 1 were based on manufacturing experience. Visual test/inspect is typically about 10 percent of fabrication labor. Visual and vibration are about 15 percent of fabrication labor.

(4) Handling Labor - The estimating relationship is:

(mount weight in pounds) ( $g^{\circ}$ ometry) (manufacturing factor)(handling factor) (Quantity) -.152 $^{-152}$ 
The handling factor $=\$ 3 /$ pound, if fixed mount $\$ 6 /$ pound, if movable.

(5) Tooling and Equipment - The non-recurring cost to design and fabricate tools and prepare numerical control machine tapes is:

$$
\text { (mount weight in pounds) }(\$ 26 / \text { pound) }(R) \cdot 3
$$

This relationship was taken from reference 1 assuming machined steel construction.

$R$ is the planned peak production rate in units per month.

FMS equipment typically costs $\$ 500,000$ per machining center (Reference 5). Two centers were assumed: one for machining and another for the installation of motor drives, etc. The total equipment cost for FMS is therefore $\$ 1,000,000$. This cost assumes that the contractor already has an infrastructure of automated guided vehicles and an automated storage and inventory system. Additional work is needed to relate the number of machining centers to mount size and production rate.

\subsubsection{Replicated Mirrors}

Replicated mirrors are discussed as a separate category here due to several unique elements of their manufacturing process. The process includes production of an optically precise solid glass replication master, metal (or even other stiff material) substrates, and the replication layers including an epoxy-based binding material and coating material. The process for producing replicated mirrors is discussed in the next section.

(1) Master Blank - The master is essentially a high-quality glass surface that is used as a replication stamp for the replicated mirror. The surface of the master is the inverse of the final desired mirror shape. Enough masters are to be constructed to support the production rate of replicated mirrors. Masters must be refurbished after 10 replications as the surface figure degrades beyond required specifications.

The raw material costs, foundry labor costs, and all other associated labor costs are estimated as:

(master weight in lbs)(\$19/lb)(number of blank masters) 
The number of blanks term is estimated from the peak planned production rate. An approximate relationship for the number of blank masters is:

$$
\text { (program quantity)/(program schedule in months)(.05 months per unit) }
$$

Where the first portion of the expression approximates the planned peak production rate by the average rate. The relationship is approximate in that it assumes that each master can be refurbished an unlimited number of times. The .05 months/unit term is an estimate of how long a master is required per finished replicated mirror (about 40 hours out of 720 per month). The relationship excludes figuring and polishing the mirror blank which is estimated in the next paragraph.

(2) Master Figuring/Polishing - For master blanks, factory labor, materials, handling, and inspection labor are estimated with the relationship:

$$
(\mathrm{FF})(\mathrm{D} / 31)^{1.15} \text { (number of masters) }
$$

In this relationship, $\mathrm{D}$ is the diameter of the master in inches if circular and the diagonal length if rectangular. The number of masters is as estimated above. The Figure Factor, or, FF is as follows:

$$
\begin{aligned}
\text { FF }=\quad & \$ 6,280, \text { if plano master } \\
& \$ 28,850, \text { if concave master } \\
& \$ 37,000, \text { if convex master. }
\end{aligned}
$$

(3) Master Tools/Equipment - It is assumed that one planetary polisher would suffice for the construction of the masters and their refurbishment. The cost for one polisher is $\$ 2,500,000$.

The mold for the master is estimated with the relationship:

$$
\text { (master weight in Ibs) }{ }^{71} \text { (\$2440) }
$$

Existing furnaces were assumed adequate for the production of masters.

(4) Substrate Blank Fabrication - The substrate blank was assumed to be aluminum. The costs for raw materials, factory labor, handling, and inspection are estimated as:

(substrate weight in $\mathrm{lbs})(\$ 40 / \mathrm{lb})\left(\right.$ (quantity) $_{848}^{-.152}$ 
Quantity refers to the total number of units to be produced. The relationship estimates the average cost for that production quantity.

(5) Tooling/Equipment for Substrate - The non-recurring cost for a sintering furnace is calculated as:

(planned peak production rate in units/month)/(50)(\$50,000/furnace)

The relationship assumes that four aluminum substrates may be processed simultaneously. If the peak rate is not an integer multiple of 50 , the ratio should be rounded up before multiplication by the $\$ 50,000$ term.

The non-recurring cost to design and manufacture molds is:

(substrate weight in $\mathrm{lbs})^{.71}$ (peak rate in units/month)(\$240/lb)

(6) Replication Layers - The cost element includes recurring fabrication labor, materials, handling labor, and inspection labor required to deposit all of the material layers and the cost to refurbish the master. The portion related to refurbishing the master is:

$$
(R F)(D / 31)^{1.15}(\text { Quantity)/(10) }
$$

$\mathrm{D}$ is the master diameter in inches if round and the diagonal if rectangular. The Refurbishment Factor (RF) is as follows:

$$
\begin{aligned}
\mathrm{RF}= & \$ 1,900 \text { for plano master } \\
& \$ 8,655 \text { for concave master (convex mirror) } \\
& \$ 10,930 \text { for convex master (concave mirror) }
\end{aligned}
$$

Quantity is the total number of finished replicated mirrors to be produced. The factor of 10 assumes that a master must be refurbished after 10 replications. The cost per refurbishment is $1 / 3$ the cost of the initial figuring and polishing based on BDM experience. Again, it was assumed that an unlimited number of refurbishments can be tolerated on any master. 
The cost for deposition of the replicated layers is estimated as:

\section{$(\$ 4.50)(D)^{2.1}$ (Quantity) -.152 \\ .848}

In this relationship, $\mathrm{D}$ is the diameter in inches for round mirrors and diagonal in inches for rectangular mirrors. Quantity is the cumulative number of units produced. 


\subsection{MURROR BLANK FABRICATION}

The fabrication costs of several types of blanks have been examined by definition of fabrication processes, then analysis of costs associated with the process for that particular type of blank. The five types of mirror blanks examined are:

(1) Solid Mirror Blanks

(2) Lightweight Mirror Blanks

(3) Replicated Mirror Master Blanks

(4) Metal Mirror Blanks

(5) Foam Glass Blanks

\subsubsection{Solid Glass Mirror Blank and Window Eabrication_Process}

Figure 2.4.1-1 depicts the manufacturing process for solid glass mirror blanks. The process is similar for PYREX ${ }^{\circledR}$ windows. This process works for materials such as borosilicate glass (PYREX ${ }^{\circledR}$ ), ZERODUR ${ }^{\circledR}$, and ULE ${ }^{\mathrm{TM}}$. The process would also work for fused silica, except that boules of fused silica are grown to near-net shape, then sliced (like bread) at the required thickness instead of melting and pouring molded glass blanks as for the other materials.

The general process for fabrication of solid glass mirror blanks is described as follows:

(1) Net-shape molds are prepared from either refractory materials or from high temperature metal lined with refractory materials. The molds may be either plano or spherical as required. These molds are pre-heated to a temperature close to that of the melted raw glass.

(2) The melted glass is poured into the mold or solid raw glass material is placed into the mold.

(3) The mold then goes into the annealing oven where the annealing and cooling time, based on blank volume and size, can take from 2-3 days up to a week for a large, thick blank.

(4) The cooled blank is removed from the mold and trimmed to final shape.

(5) The blank is cleaned and inspected. Visual inspection to identify visible structure flaws is performed on each blank. Stress testing may be performed on each blank, but is more typically performed on one out of a batch run to identify any potential structural flaws not 


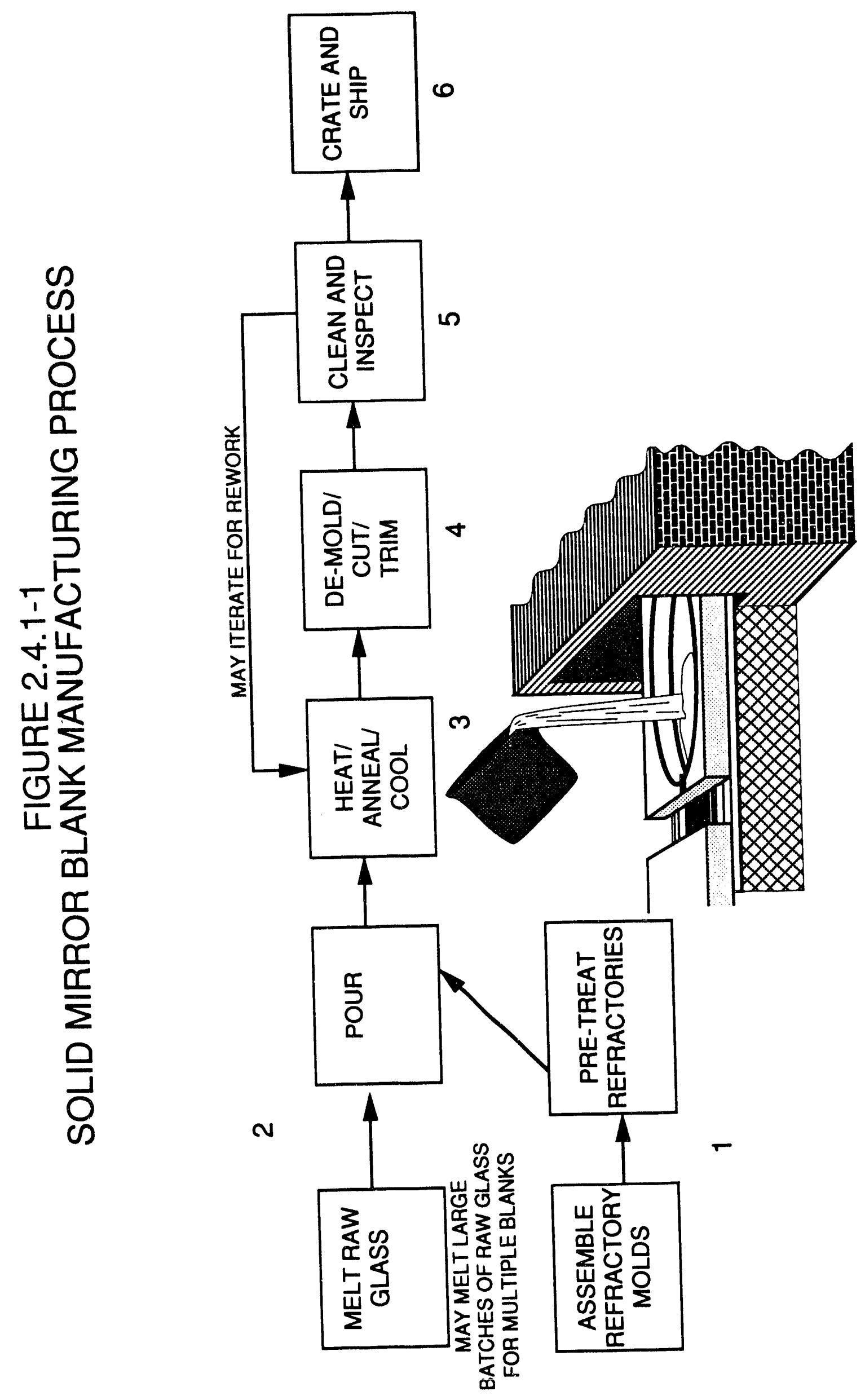


identified during visual inspection. Blanks which have flaws may be either re-annealed, or the materials recyled as raw glass. There is, however, no raw material recovery for fused silica.

(6) Finally, the blank is crated and shipped to the polishing/figuring subcontractor. Some suppliers melt enough glass to make several blanks at once. This batch-melt approach is cost effective, provided that sufficient annealing ovens already exist to anneal a batch of blanks at once. If implementing a batch-melt approach for the first time, however, the cost of building additional annealing ovens (at $\$ 30 \mathrm{~K}$ to $\$ 100 \mathrm{~K}$ each) may be prohibitive. Another process implemented by some suppliers is to produce blanks one-at-a-time by placing raw solid glass material directly into the mold, placing the mold into a melt/annealing/cooling oven, performing the melt in the mold itself, then annealing and cooling. This is also cost effective from the standpoint of minimizing the quantity of costly annealing ovens, but does not lend itself to high quantity output requirements which may be dictated by a tight schedule. In other words, the batch-melt process is a parallel process by which many blanks are processed simultaneously. It is relatively expensive if new ovens have to be built, but will assure completion on a tight schedule. The process of manufacturing blanks one-at-a-time is less costly, but does require more time to complete. For a given budget and schedule, there is probably some combination of number of annealing ovens required versus schedule requirements that will be most cost effective.

\subsubsection{Lightweight Mirror Blank_Fabrication_Process}

Figure 2.4.2-2 depicts the manufacturing process for lightweight glass mirror blanks such as those provided by HEXTEK and Kodak. The HEXTEK and Kodak process are illustrated here as being representative of the two major processes utilized today for the production of lightweight mirrors. The HEXTEK process is similar to the process used by Corning in the production of $\mathrm{ULE}^{\mathrm{TM}}$ lightweight mirrors. Lightweight mirror blanks, like solid mirror blanks, may be made from materials such as borosilicate glass (PYREX ${ }^{\circledR}$ ), ZERODUR ${ }^{\circledR}$, and ULE ${ }^{\mathrm{TM}}$.

The general process for fabrication of lightweight glass mirror blanks is described as follows:

(1) HEXTEK - It is assumed for this process that a large quantity of lightweight structural "tubes" is in inventory. These tubes are cleaned, and assembled into a refractory mold. Refractory tooling is used both in the manufacture of the tubes and to maintain structural integrity during annealing of the entire blank. Front and back glass plates are cut to final shape, drilled, and cleaned. 


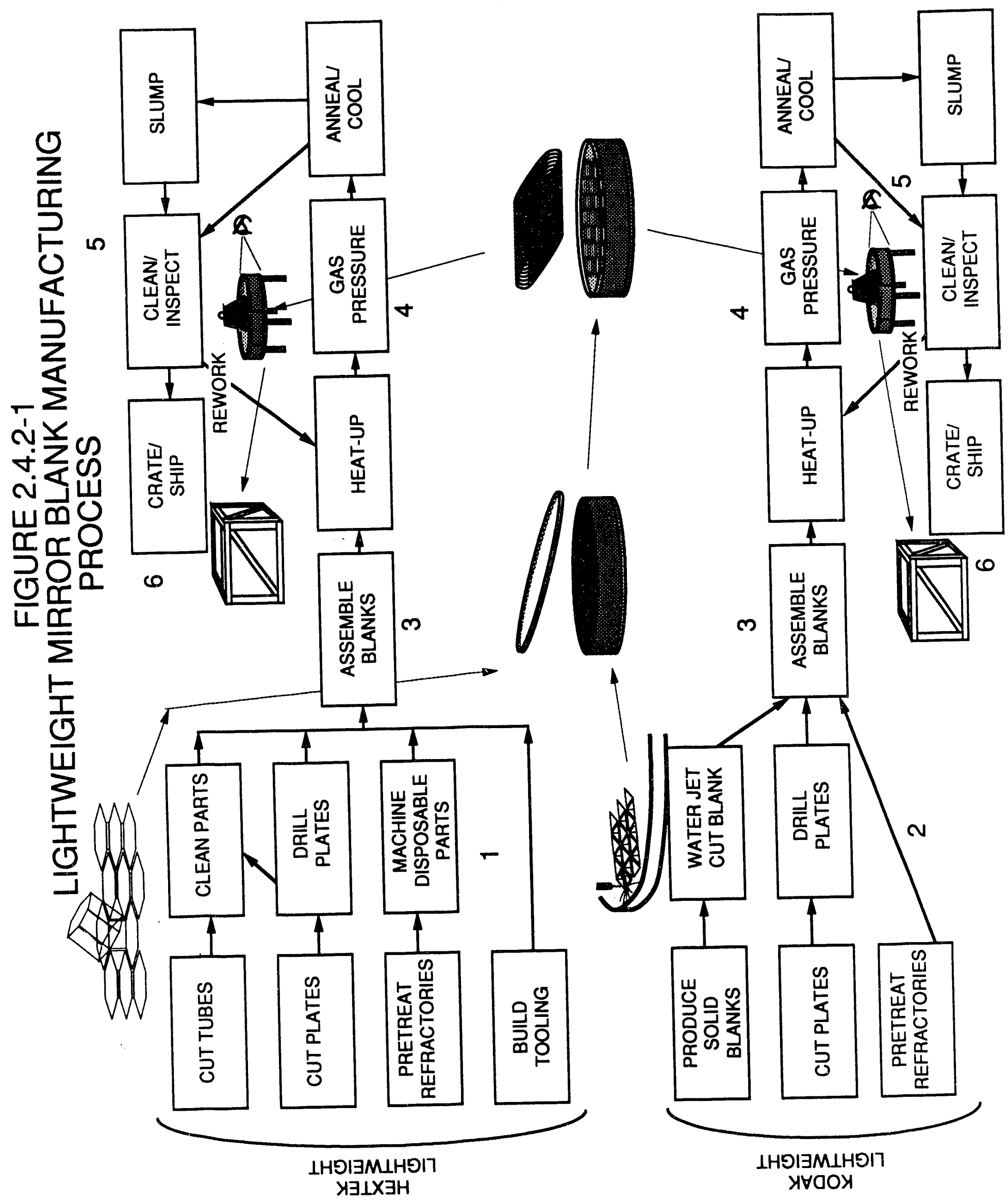


(2) Kodak - The lightweighting structure is cut into a solid glass blank (plano or spherical) by a high pressure water jet. Front and back glass plates are cut to final shape, melted to conform to spherical shape if needed, drilled, and cleaned.

(3) The blanks (HEXTEK and Kodak) are assembled in a refractory mold. The front plate is inserted on the bottom, followed by the lightweight structure(s), and topped with the drilled back plate.

(4) The mold then goes into the annealing oven where the annealing and cooling time, based on blank volume and size, will typically take 5 days.

The cooled blank is cleaned and inspected. Visual inspection to identify visible structure flaws is performed on each blank. Stress testing may be performed on each blank, but is more typically performed on one out of a batch run to identify any potential structural flaws not identified during visual inspection. Blanks which have flaws may be either re-annealed, or the materials recyled as raw glass. There is, however, no raw material recovery for fused silica.

(6) Finally, the blank is crated and shipped to the polishing/figuring subcontractor. Rough figuring for spherical blanks is performed during blank fabrication.

Major differences exist in the fabrication processes for HEXTEK, Corning, and Kodak lightweight mirror blanks. The HEXTEK and Corning processes are similar, however, HEXTEK builds its lightweight structure out of pre-shaped hexagonal, square, or triangular closed cells which are bonded during annealing. Corning machines delicate sheets of ULE which are fritbonded into the lightweighting lattice structure. The Kodak process, on the other hand, starts with a solid blank (which has it's own assembly process (see 2.4.1)), then cuts the lightweight structure with a waterjet cutter - a precise process but which may take as long as two weeks of continuous cutting.

The pros and cons of each of the three lightweight mirror fabrication processes are specified below

HEXTEK PROS:

- Closed cell structures are produced as a whole piece (no assembly of cell required)

- HEXTEK claims bonding strength advantages over Corning frit-bonding 
- Inexpensive refractory tooling for forming cell structures may be used up to 10 times, then repaired and re-used

- Lightweight mirrors are approximately $1 / 4$ the weight of solid blanks of same material at a competitive cost

- HEXTEK has an outstanding field record in laser applications.

\section{HEXTEK CONS:}

- HEXTEK blank edges are extremely fragile and require special handling (same for all lightweight blanks).

\section{CORNING PROS}

- ULE is extremely stable in high temperature laser environment

- Lightweight mirrors are approximately $1 / 4$ the weight of solid blanks of same material at a competitive cost.

\section{CORNING CONS}

- Frit-bonding is a time consuming, meticulous process which does not lend itself well to automation. The Corning process is the most laborintensive lightweight blank fabrication process

- Corning lightweight is not as strong as HEXTEK

- Corning blank edges are extremely fragile and require special handling (same for all lightweight blanks)

\section{KODAK PROS}

- Lightweight structure is cut from solid blank by a water jet - no heat required, completely automated

- Lightweight structure has no assembly bonds - may be stronger than HEXTEK or Corning

- Lightweight mirrors are approximately $1 / 4$ the weight of solid blanks of same material at a comparable cost.

\section{KODAK CONS}

- Waterjet cutting of a single blank may take one - two weeks, still needs annealing when plates are attached. 
- Process is more time consuming than HEXTEK or Corning

- Kodak lightweight blank edges are extremely fragile and require special handling (same for all lightweight blanks)

\subsubsection{Replicated Mirror Fabrication Process}

The fabrication process for replicated mirrors is unlike all other technologies examined in this report. This section therefore discusses the complete process of producing replicated mirrors including master and substrate blank fabrication and coating to final product. Replicated mirror masster blanks are solid glass mirror blanks, typically PYREX. These blanks are polished as for other solid mirrors, but remain un-coated. The process for producing these blanks is essentially the same as for producing other solid mirror blanks (described in 2.4.1). Substrate blanks are essentially metal mirror blanks, typically aluminum, copper, beryllium, or silicon carbide. While other materials may be used such as composites, glass, or other metals, they are not examined in this study. The process for producing these substrates is the same as for producing metal mirror blanks (described in 2.4.4).

The complete process currently in use by Balzers Optics Company for producing replicated optics is depicted in figure 2.4.3-1. This process description assumes a supply of metal substrates and glass blanks is available to meet peak production rate requirements. The cost reduction methodology does, however, account for the production of metal substrates and glass replication blanks to meet peak production loads.

The general process for fabrication of replicated mirrors from metal substrates and replication blanks is described as follows:

(1) Replication layers are applied to the glass master. The glass master is covered by a release layer that keeps the finished replicated mirror from sticking to the master. The release layer is followed by a layer of protective material to minimize damage to the coating layer which is applied next. Finally, the adhesive epoxy layer is applied immediately before the metal substrate is pressed into the layers.

(2) The metal substrate is pressed onto the layered master and cured at a relatively low temperature $\left(150-160^{\circ} \mathrm{C}\right)$ for up to 24 hours.

(3) The substrate is lifted from the glass master and the layers will have transferred to the substrate resulting in a finished replicated mirror. The master is then inspected for damage 

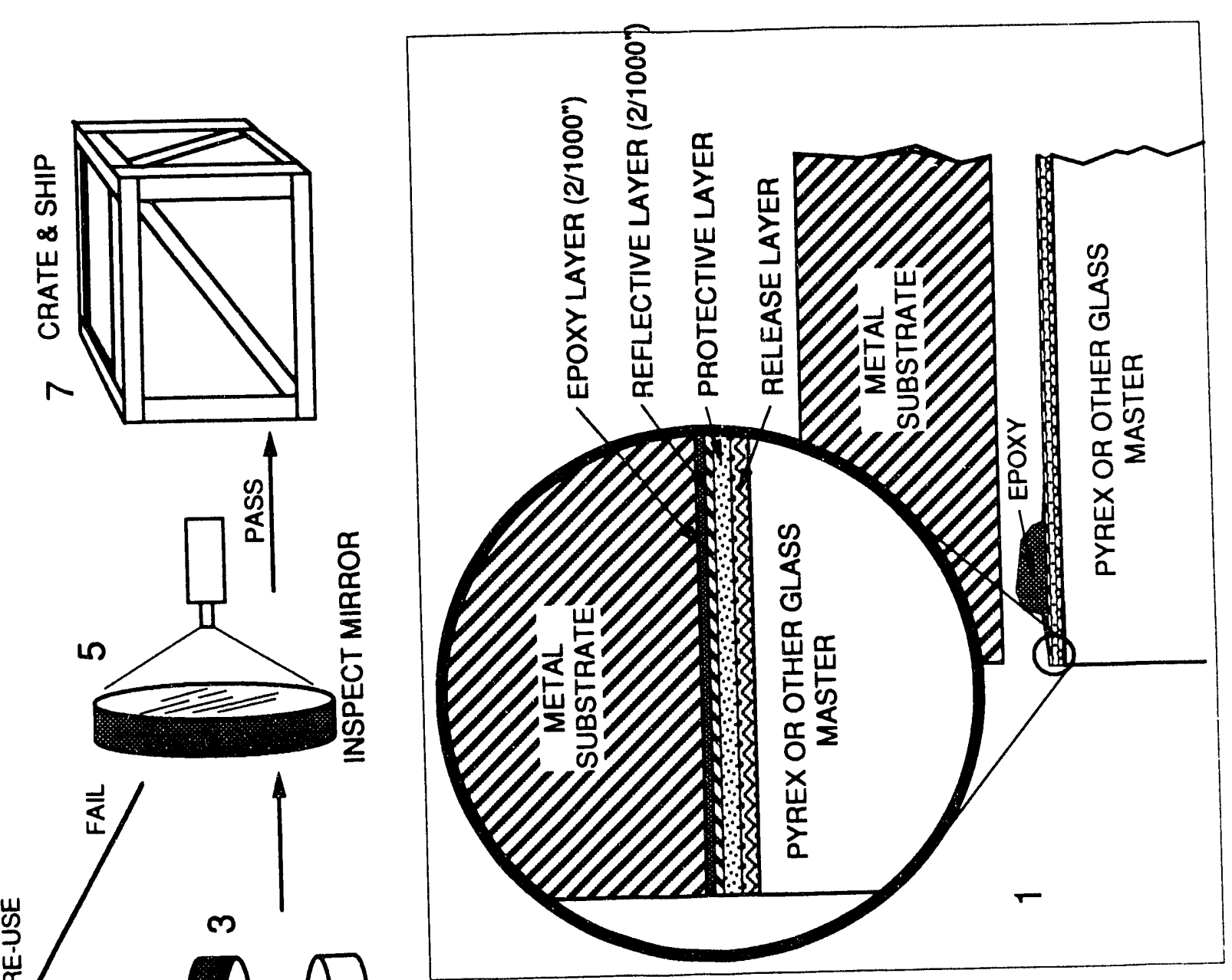

중

(1)

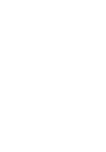

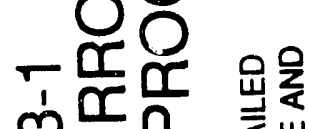

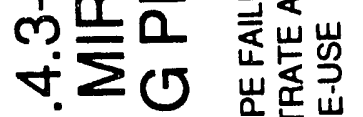

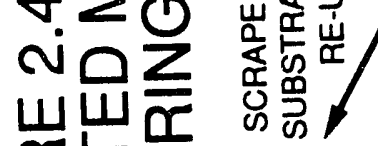

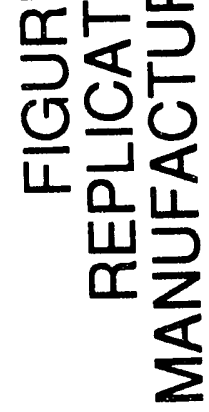

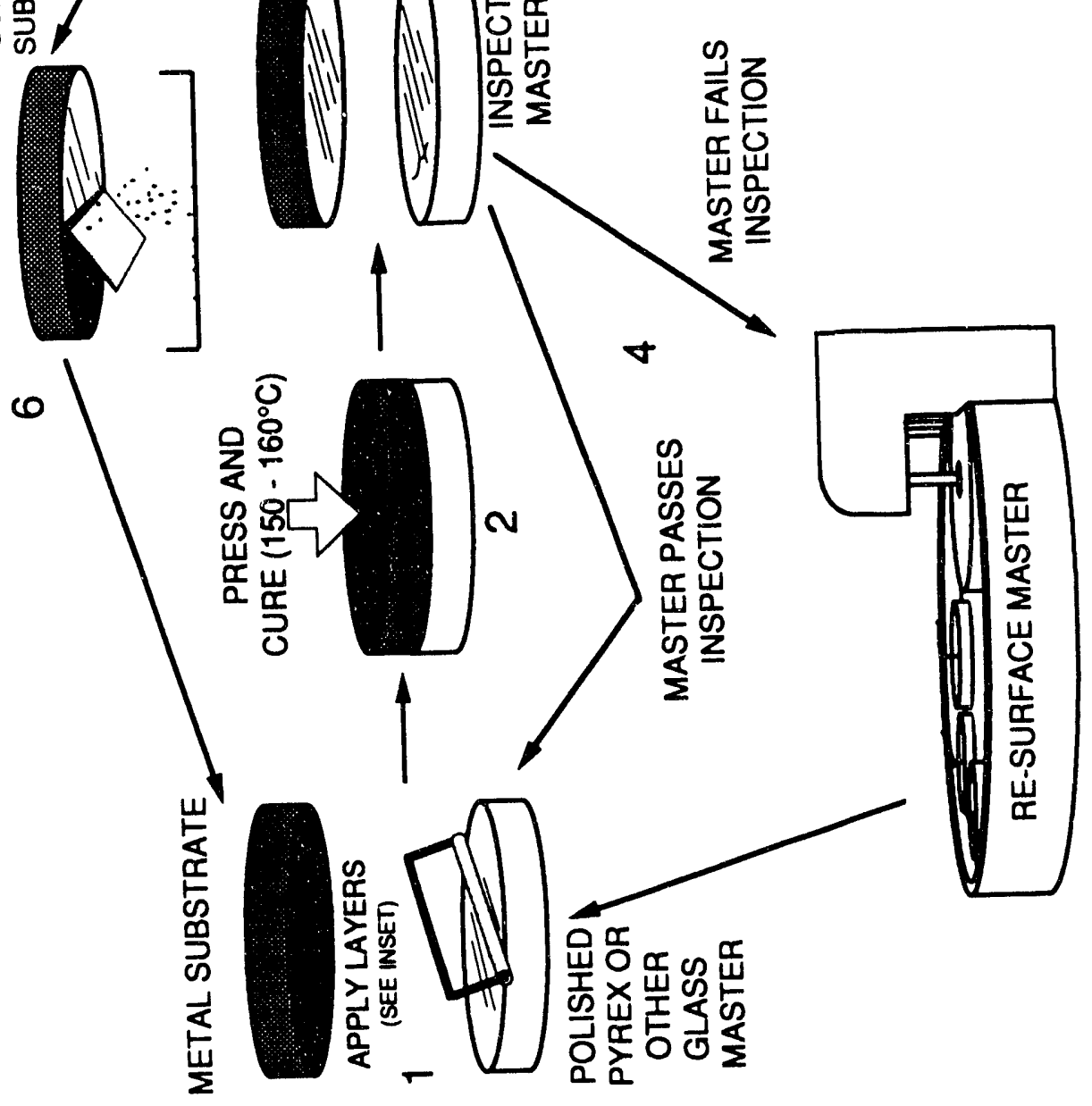


during replication. Typical damage would include either scratches or chunks of the master surface which stuck to the replicated mirror surface. If the glass master fails the inspection, it is re-figured and polished to original specification

(4) If the glass master fails the inspection, it is re-figured and polished to original specification. If it passes, it is merely re-used in the next replication.

(5) The replicated mirror is inspected. A mirror which passes inspection is finished and ready for shipping. A mirror which has failed will have its layers scraped off and the mirror (now a substrate) is re-entered into substrate $n v$ sitory.

(6) Finally, the finished replicatec mirror is crated and shipped to the polishing/figuring subcontractor.

Replication is by far the least expensive of all optics alternatives examined in this study (assuming $\mathrm{Al}$ or $\mathrm{Cu}$ substrates). However, current replication technology is fraught with may physical shortfalls. The major shortfall is that the epoxy adhesive shrinks approximately $5 \%$ during curing. This induces a surface stress that can tear and damage the reflective surface over time. Additionally, replic:sed optics have not been studied in high energy ultra violet and vacuum environments. Epoxy, like many organic compounds may out-gas in a high-temperature vacuum and degrade beyond specification in the ultraviolet light. Studies are being conducted by the USAF Wright Patterson AFB Materials Laboratory on new epoxies that do not shrink or degrade over useful life. Perhaps, in 10-20 years, most of these types of problems in replicated optics will be addressed.

Replication, however, also has its advantages. Metal mirror substrates are proven to be cost effective if certain materials are used. Here, replicated mirrors physically compare almost equally with metal mirrors in that they are relatively lightweight and that they can have mounting fixtures molded right into the substrate. As with metal minors, the cost of the substrate material is relatively inexpensive for copper and aluminum but very expensive for silicon carbide and beryllium. Additional costs savings may be realizeul through the use of metal forming technologies such as net shape forging. This proven technology would eliminate some of the machining and even molding/sintering steps of traditional metal substrate fabrication.

Glass masters may be used as many as 10 times before they must be refurbished. The cost of refurbishing is much less than polishing a new glass blank. However, glass masters must have a 1/20 wave surface to obtain $1 / 10$ wave replications. This represents a smail increase in the time the master spends on the polisher. 


\subsubsection{Metal_Mirror_Blank_Eabrication Process}

Figure 2.4.4-1 depicts the manufacturing process for metal mirror blanks such as those provided by United Technologies and Kodak. Metal blanks may be made from materials such as Silicon Carbide, Beryllium, Aluminum, or copper.

The general process for fabrication of metal mirror blanks is described as follows:

(1) Net-shape molds are refractory materials such as high temperature ceramics or from high temperature metal which are then lined with refractory materials. The molds may be either plano or spherical as required. These molds are then cleaned.

(2) A ball mill is used to pelletize and powder the raw metal blank substrate material (usually aluminum, silicon carbide, or beryllium, but may be magnesium) slip which is then poured into the mold. The liquid portion of the slip is evaporated out of the mold leaving the powdered metal blank material.

(3) The mold then goes into the sintering oven which melts the powdered or pelletized metal and anneals the blank - a process which can take several hours up to a week for a large, thick blank.

(4) The cooled blank is removed from the mold and trimmed to final shape.

(5) The blank is cleaned and inspected. Visual inspection to identify visible structure flaws is performed on each blank. Also, a small portion of the blank is polished and etched to reveal material grain structure. Non-destructive hardness testing such as Rockwell or Brinell may be performed on a statistical sample from a batch of blanks or may be performed on each and every blank. Hardness testing will reveal that the hardness of the material will be amenable to polishing. Stress testing may be performed on each blank, but is more typically performed on one out of a batch run to identify any potentially structural flaws not identified during visual inspection. Stress testing on these metal blanks may include destructive testing which will be performed on only a small sample of the blanks. Blanks which have flaws may be re-sintered/melted.

(6) Finally, the blank is crated and shipped to the polishing/figuring subcontractor.

Perhaps the largest cost savings justifications in favor of metal mirror blanks is the savings in blank fabrication and mounting costs. Here, they physically compare almost equally with replicated mirrors in that they are relatively lightweight and that they can have mounting fixiures 
molded right into the blank. The cost of the blank material is relatively inexpensive for copper and aluminum but very expensive for silicon carbide and beryllium. Additional costs savings may be realized through the use of metal forming technologies such as net shape forging. This proven technology would eliminate some of the machining and even molding/sintering steps of traditional metal blank fabrication.

A batch-sintering approach is cost effective, provided that sufficient sintering ovens already exist to make a batch of blanks at once. If implementing a batch-sintering approach for the first time, however, the cost of building additional sintering ovens may be prohibitive. 


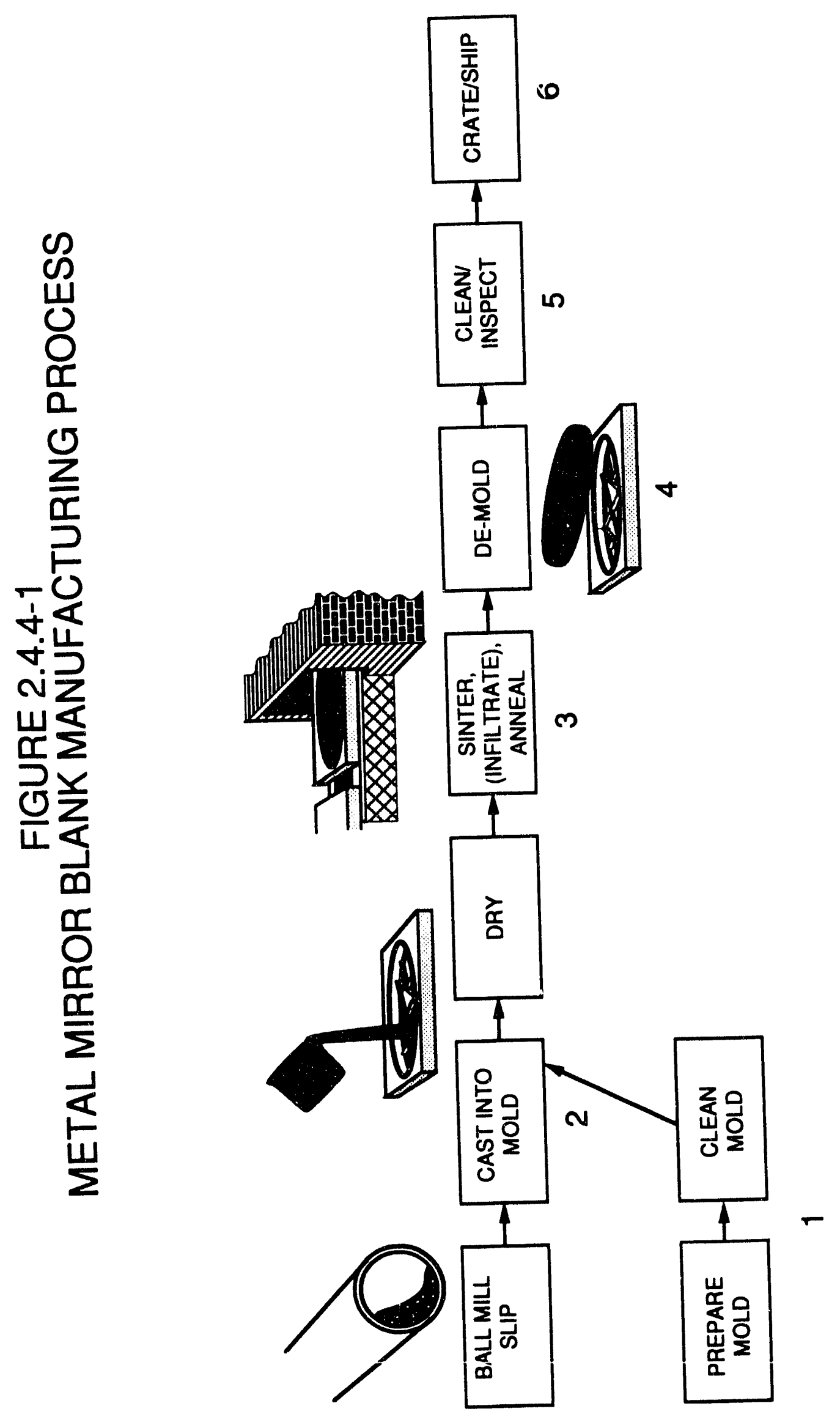




\subsubsection{Eoamed Glass Mirror Blank Fabrication Process}

Figure 2.4.5-1 depicts a suggested manufacturing process for the production of foam glass mirror blanks. Currently, mirror blanks of the specifications required for the LMF are not being manufactured, however, a process utilizing a combination of proven steps has been defined so that a cost baseline could be developed. It was felt that foamed glass should be examined as a possible future alternative since the cost model shows it to be cost competitive with lightweight (HEXTEK) mirrors.

A proposed process for fabrication of foamed glass mirror blanks is described as follows:

(1) A powdered "glass flour" is mixed with a foaming agent such as carbon powder and placed in a rectangular steel mold. Today, all foam glass is made in rectangular one foot by two foot molds.

(2) The powdered material is sintered - brought to a temperature which melts the glass flour but does not oxidize the foaming agent. The melt is then mixed to ensure a homogeneous distribution of the foaming agent.

(3) Oven temperature is raised to bake the melt and activate the foaming agent. Naturally, foam cell size can be controlled with variance of foaming agent type and quantity, and temperature. The foamed glass is annealed and allowed to cool slowly.

(4) The cooled foam substrate is removed from the mold and trimmed to needed shapes. In addition, front and back plates are cut and trimmed. Because the foam cell size is so small, print-through on the plates is not a problem. The plates may therefore be much thinner than with traditional lightweight mirror blanks.

(5) The blank is assembled by piecing cut foam and plates together for form the blank.

(6) The assembly is re-heated to bond the components and anneal the bond. Traditional bonding such as frit bonding may be used.

(7) The cooled blank is tested using traditional structural and visual methods. In addition, cell size may be measured for uniformity and adherence to specification.

(8) Finally, the blank is crated and shipped to the polishing/figuring subcontractor. 


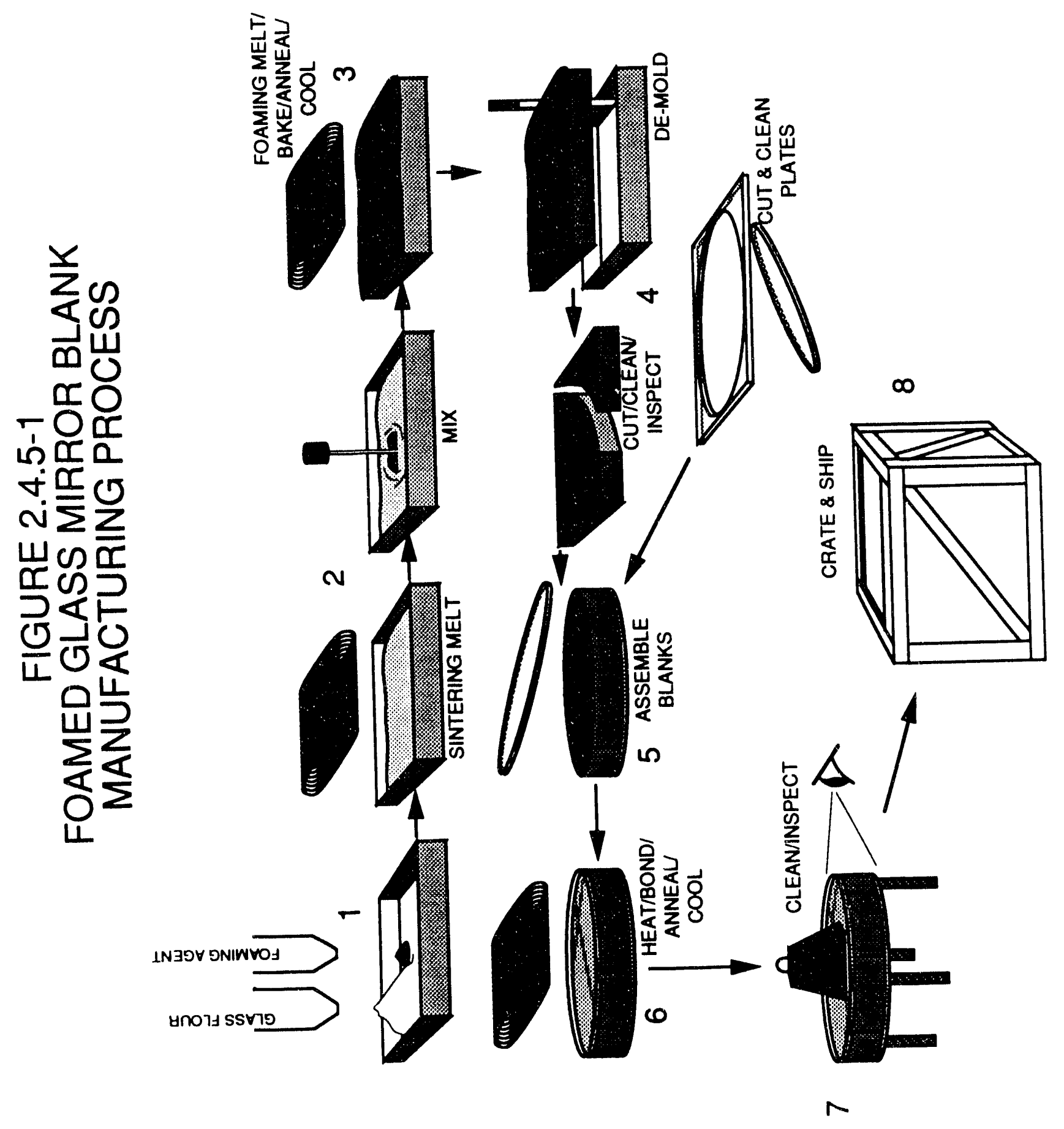


Foam glass mirror blank production costs are similar to those for solid glass. The real cost saving in producing foam glass mirrors is in mounting costs. Since they weigh approximately $1 / 6$ that of solid glass mirrors, the mount and motor drive do not have to be nearly as robust. Foamed glass has been used as structural and insulating components for many years and is aggressively being studied by the Soviet Union. Studies undertaken by the Jet Propulsion Laboratory have shown that while foam glass make a relatively good and stable mirror substrate, it does not weather well if exposed to rain and other outside elements. Coating exposed pieces would eliminate potential corrosion problems which may be encountered in the relatively clam environment of the LMF. 


\subsection{OPTICAL EIGURING}

Two types of optical figuring of plano windows and both plano and aspherical mirror blanks processes have been examined. Planetary polishing has been used for centuries as the standard method of producing high quality optics. Figure 2.5-1 depicts a modern planetary polisher. Although slow, a planetary polisher will consistently yield high quality optics with precise surface specifications, assuming that the polisher has had prior experience. The mechanical polishing process employed in planetary polishers may take up to 2-3 weeks of continuous polishing for very large optics (including test and rework). This time is dependant on the size of the finished optical component and the required surface characteristics.

An alternative to planetary figuring is ion figuring where a numerically controlled ion beam provides the final figured surface. Ion figuring takes much less time than with planetary figuring, yielding comparable results. Ion figuring machines, however, are very expensive. They provide the best alternative, however expensive, when generating large quantities of high quality optics $(>100)$.

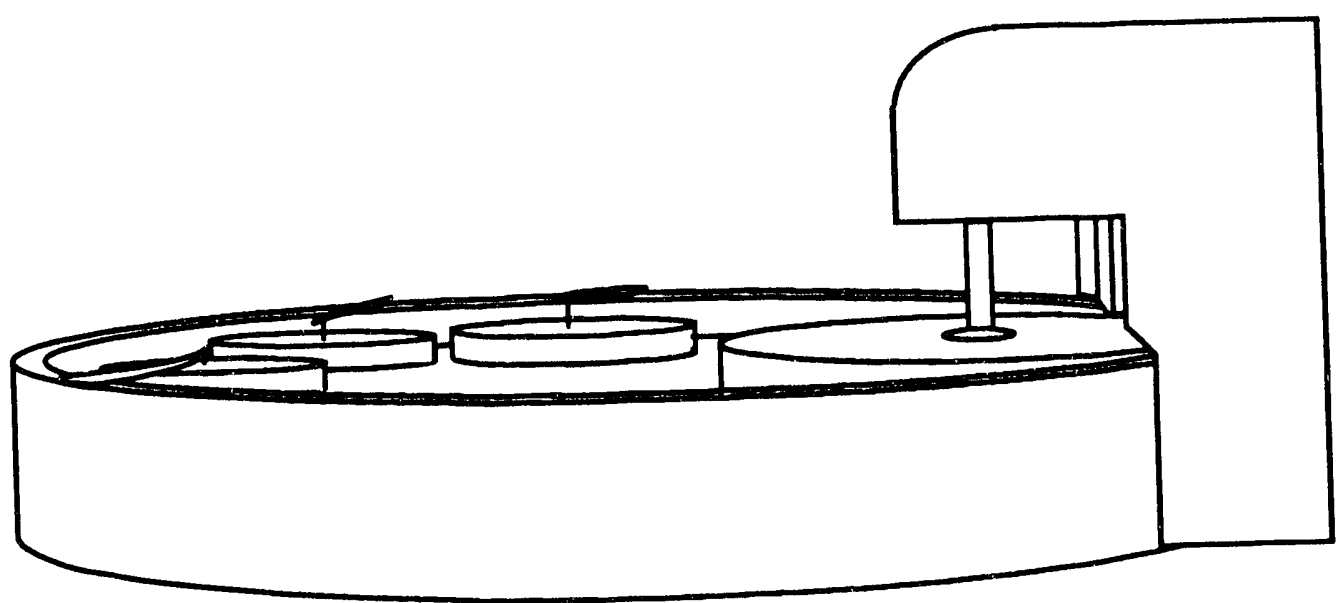

Figure 2.5-1 PLANETARY POLISHING MACHIr 


\subsection{COATINGS}

Figure 2.6-1 shows the mirror and window coating process used by most coating laboratories. This process is taken from the processed employed at OCLI and Spectra Physics, Inc. The process is described as follows:

(1) The polished mirror or window is attached to a fixture where it under-gos inspection and final cleanup.

(2) The mirror is then rolled immediately into the deposition chamber to minimize exposure to pollutants. When the chamber is heated and air is pumped out, metal ion or vapor deposition begins. At the end of deposition, the mirror is cooled and removed from the chamber.

(3) The finished mirror is then examined for surface flaws before packaging and shipping.

As one might expect, the cost of coating different types of mirrors and windows are relatively equal. This is an area where replicated optics can save significant costs. 

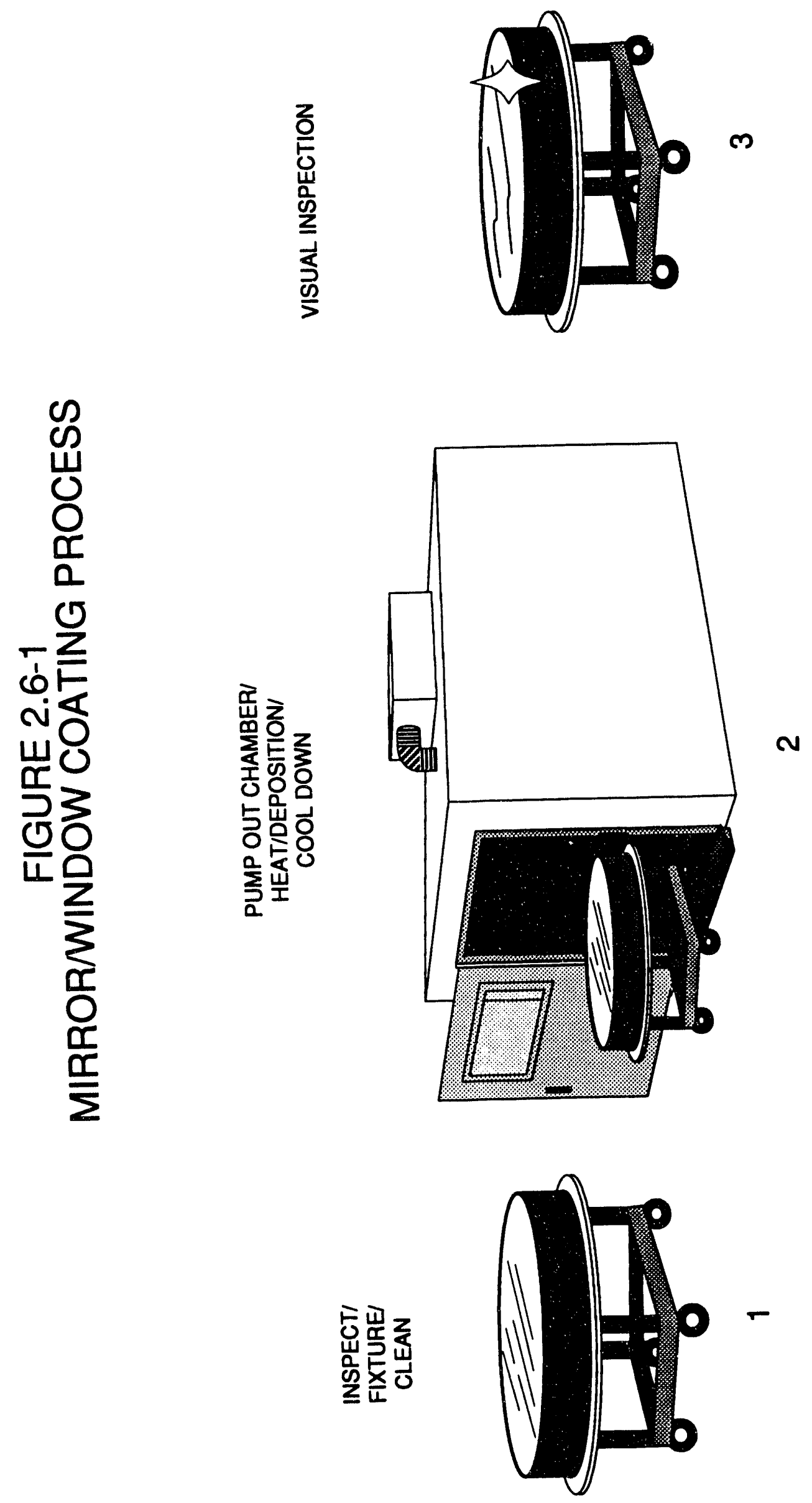


\subsection{MOUNTING}

There are a variety of mount types for large optical components. Figures $2.7-1 \mathrm{a}, \mathrm{b}$, and c show three such types of mounts. Mounting costs can account for 30 to $50 \%$ of total functional optical component costs. Mount costs are directly proportional to the weight of the component to be mounted. This means that a mount for a heavy solid glass mirror will be approximately 4 times more expensive than for a lightweight HEXTEK style mirror. By reducing mirror weight, one can use a considerably less stout mount and drive mechanism. Hysteresis oscillation of a heavy mirror is a considerable problem during motorized adjustment. It is much less a problem with lightweight mirrors.

Of all components examined in this study, manufacture of mirror mounts is the only one which truly lends itself to automation. A Flexible Manufacturing System (FMS) capable of being flexibly configured for different types and sizes of mounts would save from 25 to $40 \%$ over traditional methods. The FMS for constructing mounts would consist of numerically controlled metal stamping, bending, welding, drilling, and machining, and testing stations. Quality assurance would be designed in to obtain the maximum yield.

In this study, only metal mirror mounts were examined. Other new materials such as Anorad's Anorite, a composite with excellent structural and vibration damping properties, are very promising and should be examined in future studies. 


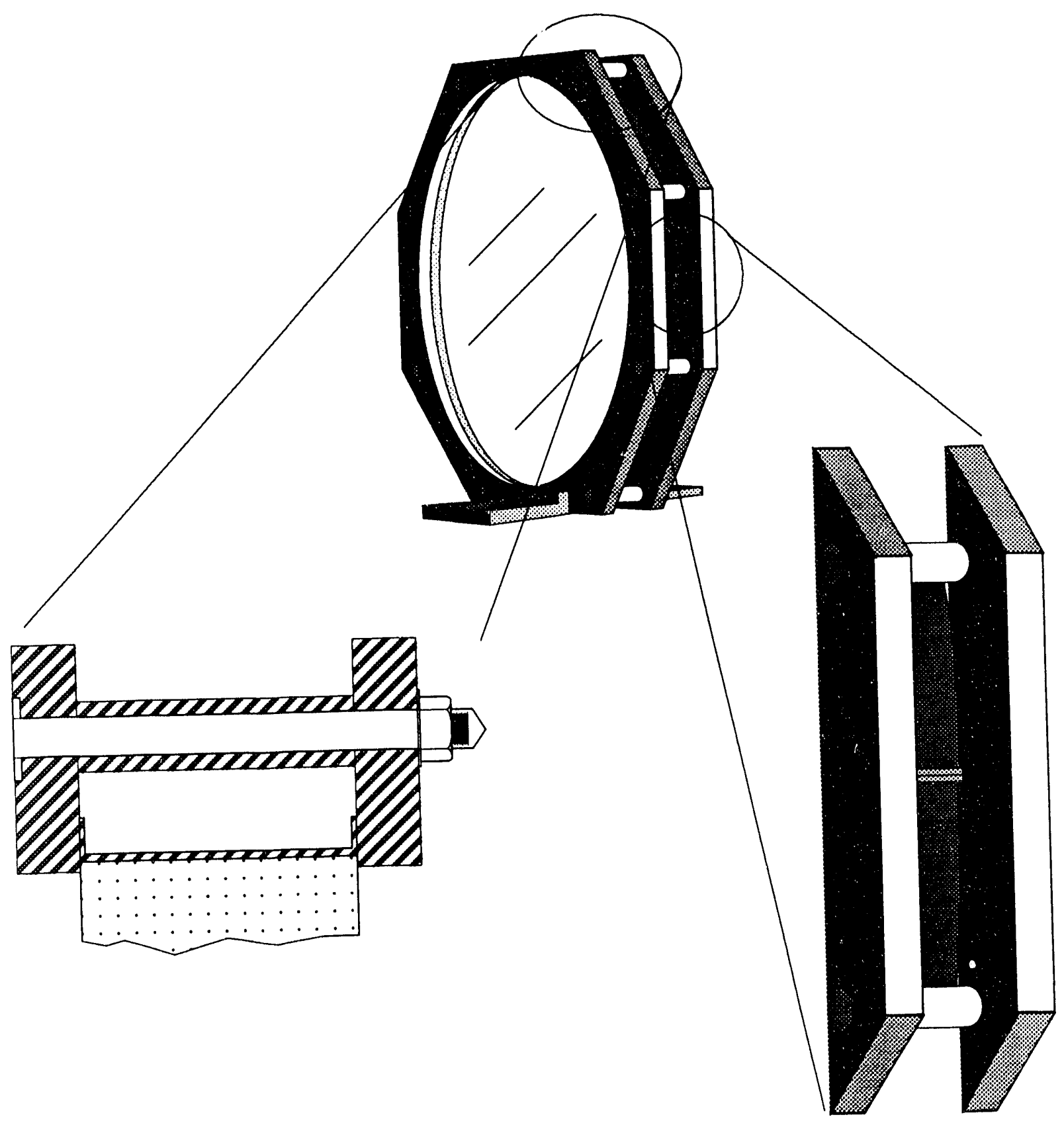

FIGURE 7.1A - Standard mount 


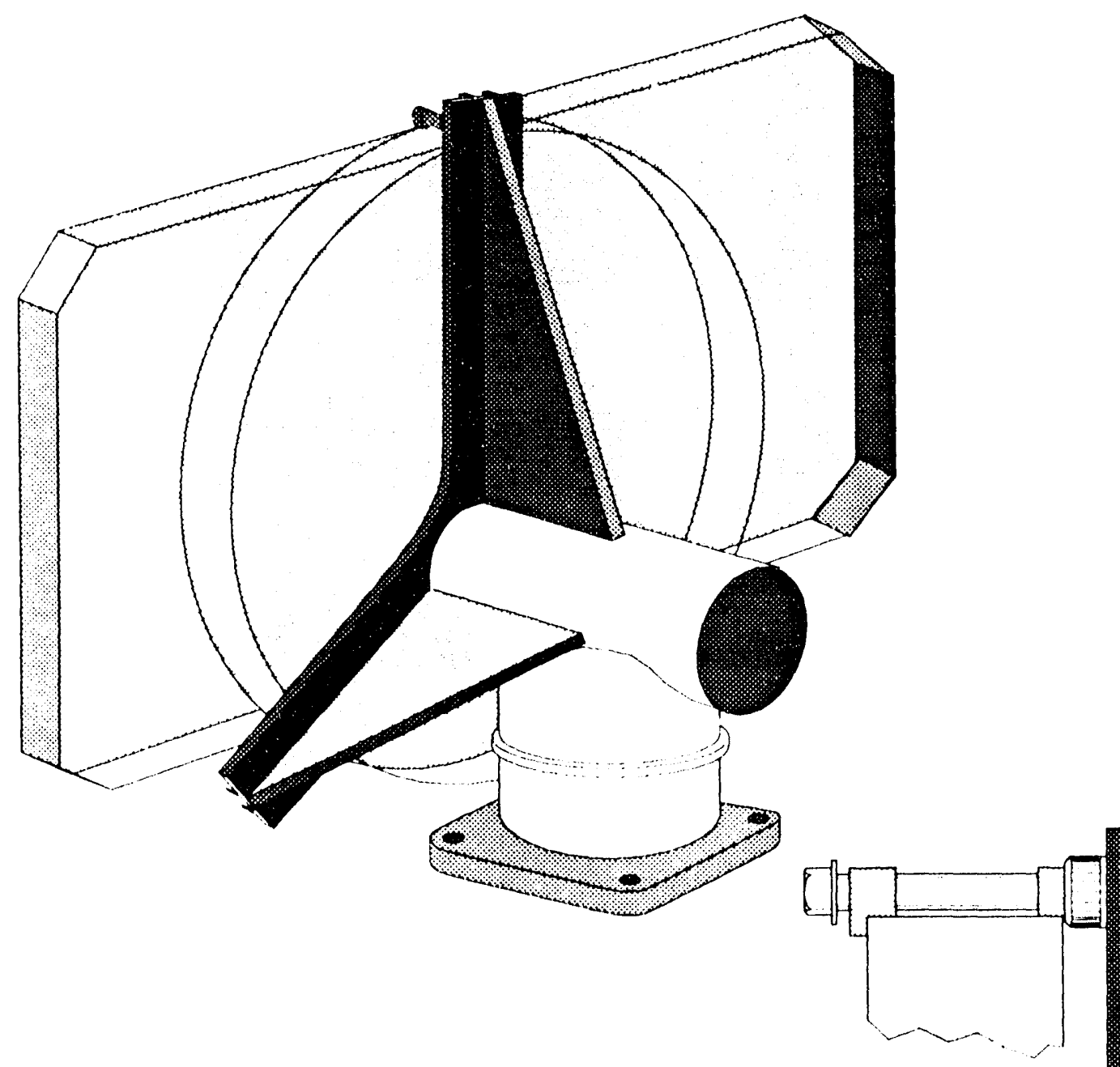

FIGURE 7.1B - Multipoint Mount

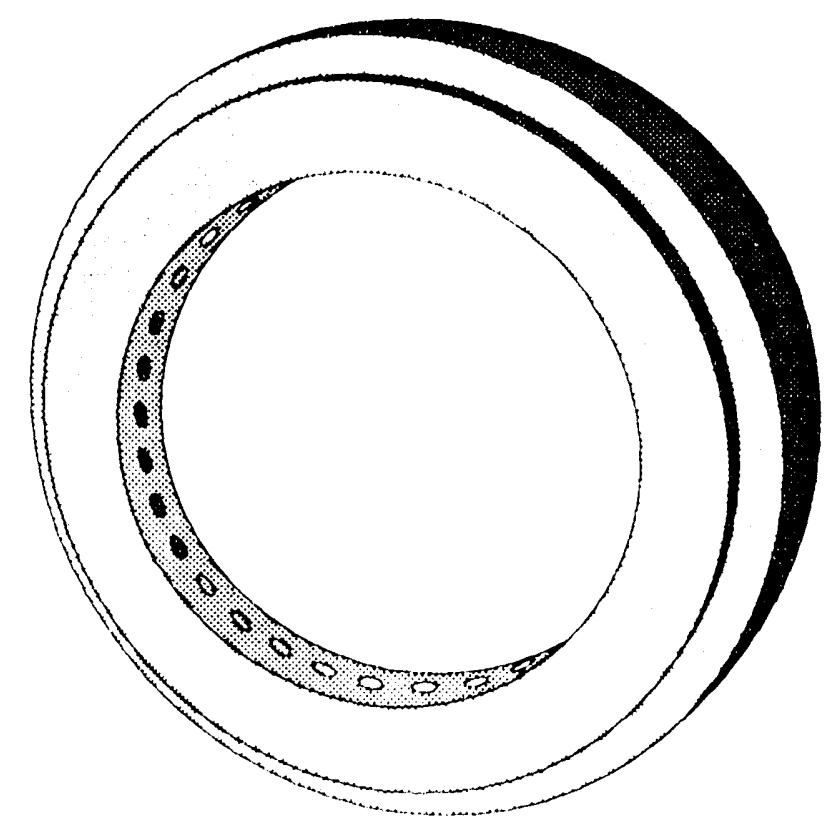

FIGURE 7.1C - Micropositioning Radial Mount 


\subsection{ANALYSIS}

This study has resulted in the development of a computer model which can be used to examine relative mirror fabrication cost trade-offs of material, manufacturing, and technology alternatives. The model is not designed to provide exact dollar cost estimates (although the results map very closely with vendor cost lists), but rather should be used to note the relative effects of changing the manufacturing and material constraints. The model is a first step toward comparing current and future trends in optical fabrication techrology and should be built upon as more data is gathered. The model does not currently examine windows.

In section 2.1, mirror types were catagorized into four major groups and quantities:

(1) Rectangular Spheres - 2070

(2) Round Spheres - 3600

(3) Rectangular Plano - 2280

(4) Round Plano - 900

The model variables have been set to these economic values:

Program schedule: 10 years (120 months)

Automated manufacturing of mounts

All mounts are motorized

Glass is regular Pyrex

Metal Mirror blanks are Copper

Ion figuring will be used where possible

The results of the model may be seen on the next four pages. 


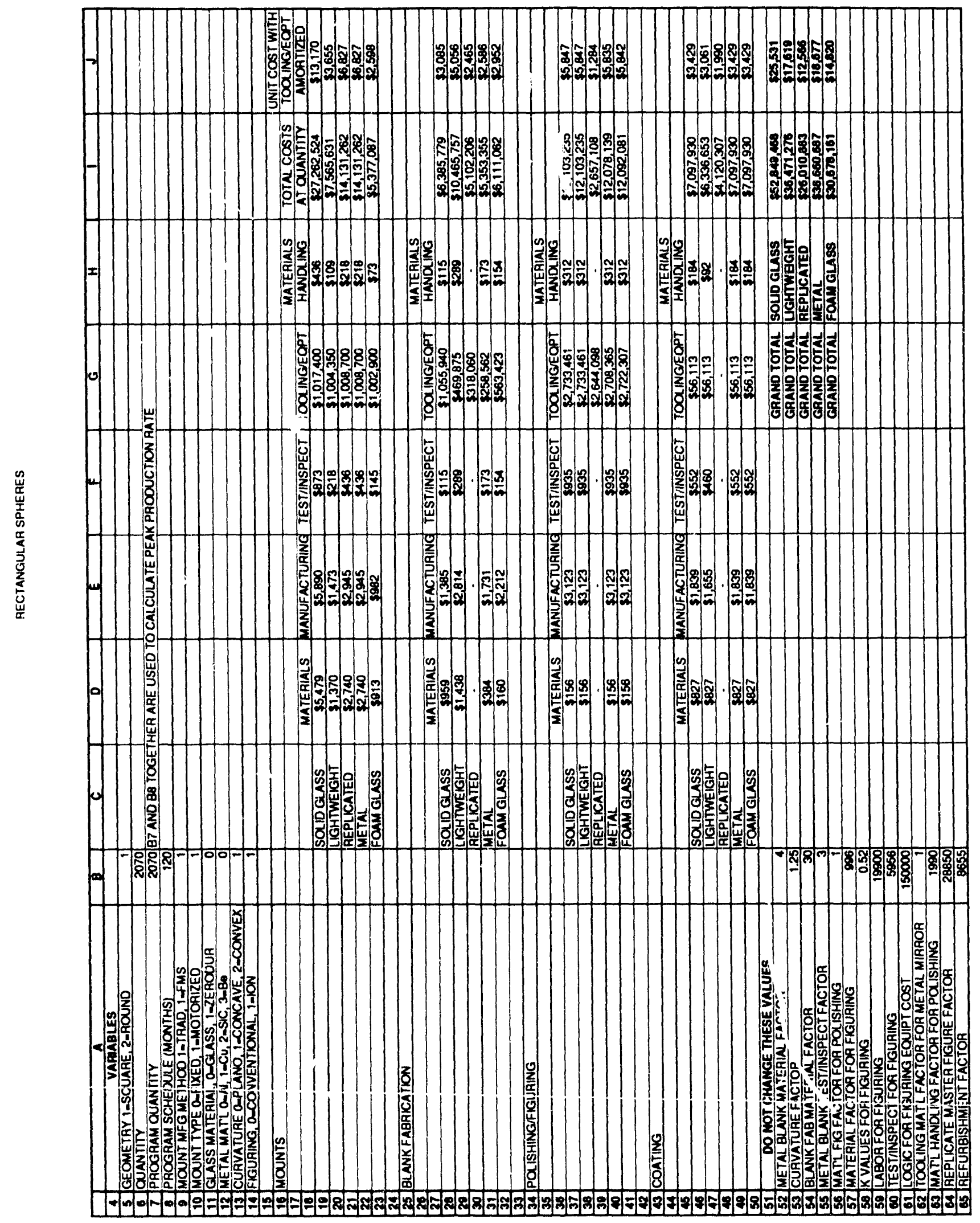




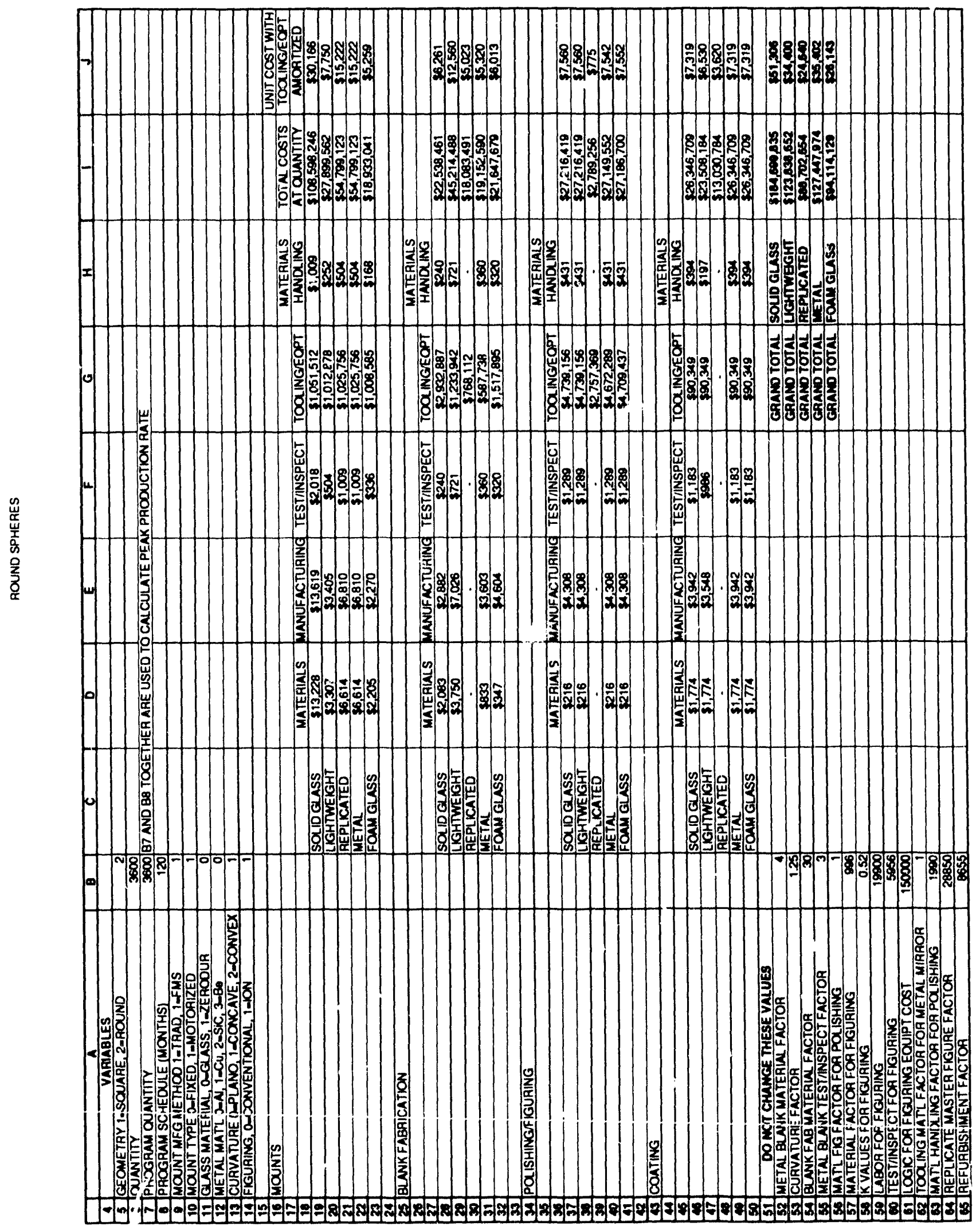




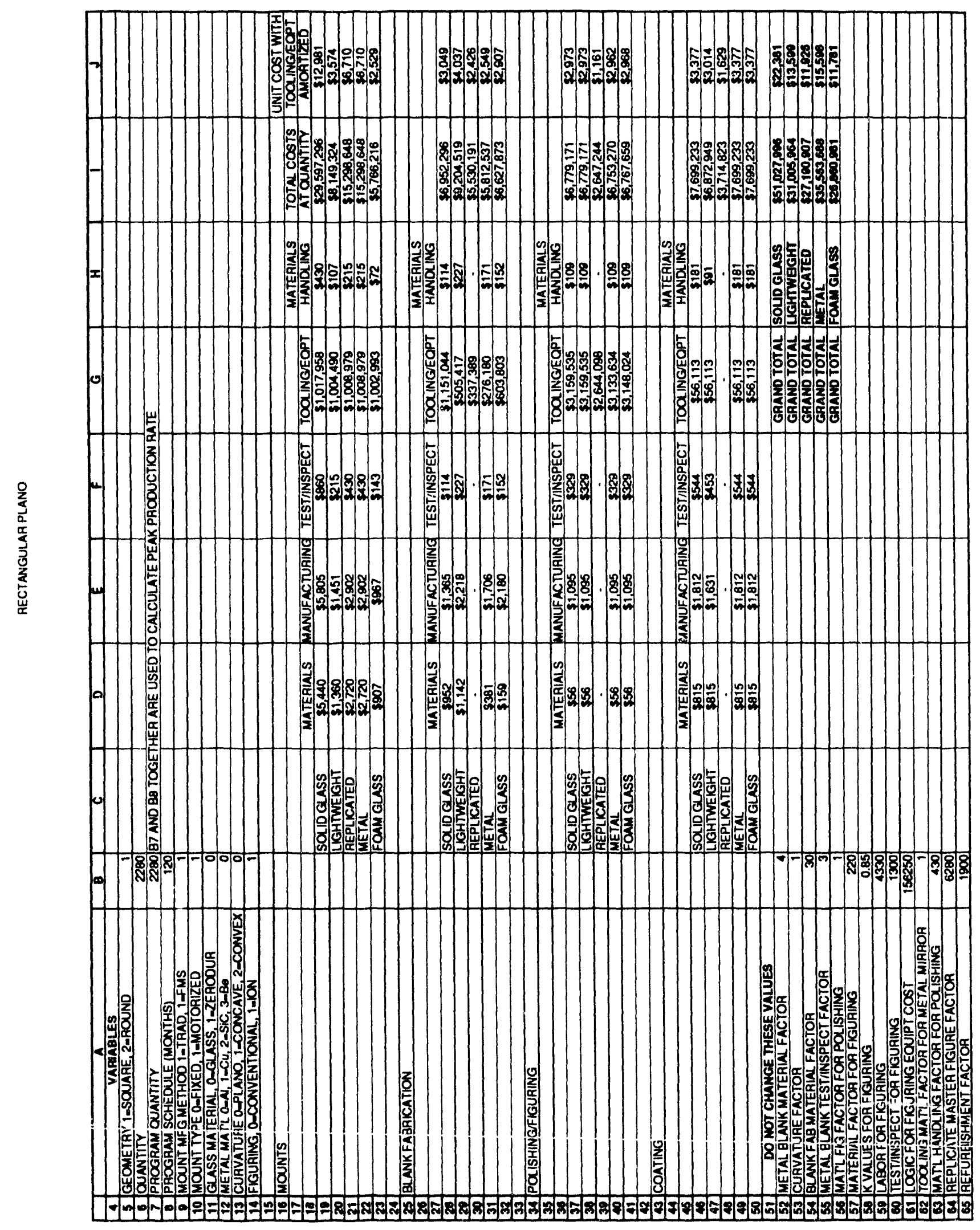




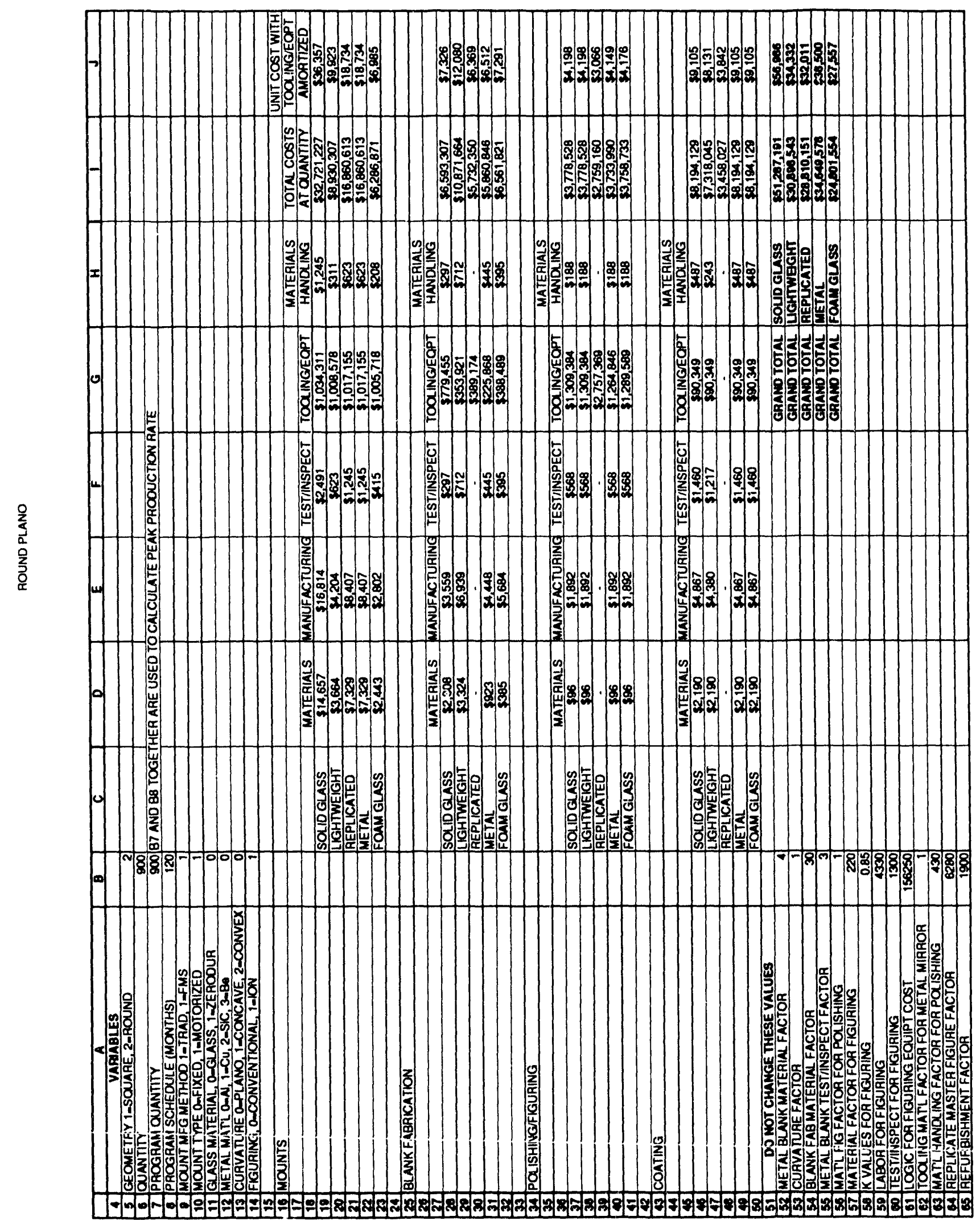




\section{SECTION 3 \\ BEAM TUBE ANALYSIS}

\subsection{BACKGROUND}

The construction of a $10 \mathrm{MJ}$ laser fusion device is being pursued by Los Alamos National Laboratories (LANL) for the development of commercial fusion power. At the present time a 10 $\mathrm{kJ}$ angular multiplexing $\mathrm{KrF}$ amplifier laser, called AURORA, has been constructed at Los Alamos. When this device is expanded to AURORA II it is expected to produce a $100 \mathrm{~kJ}$ laser pulse on the fusion target. This device will be used to develop the technology necessary for the $500 \mathrm{~kJ}$ Intermediate Driver device which in turn will be used to develop the $10 \mathrm{MJ}$ LMF device.

One of the major costs of the LMF will be the long thermally stable helium filled beam tubes for the containment of laser beams over long distances. Because the laser energy must be delivered to the target in a 5 nanosecond pulse, but the $\mathrm{KrF}$ amplifier requires a 480 nanosecond pulse, a method called angular multiplexing is used to split a single 5 ns pulse into a train of 96 sequential pulses, which appear to the amplifier as a single long pulse, and then convert the train back to 5 ns pulses that strike the target simultaneously.

In order to achieve this mulitplexing the laser pulses must be focused and de-focused, converged and separated so that they all pass through and fill the amplifier space but are traveling along independently controlled paths. Because the beams must be on essentially parallel paths through the amplifier, the actual angles between the beams are small - generally less than one degree of arc. Therefore, in order for these paths to diverge enough to be controlled by separate optical devices of real physical dimensions, they must travel long distances from the amplifier to the mirrors which orient and sequence the pulses.

\subsection{DISCUSSION}

This section discusses the cost-effectiveness of several feasible beam tube concepts. The baseline concept calls for the construction of a tube within a tube, as shown in figure 1 . This concept allows the beam tube temperature to be actively regulated without introducing a turbulent air flow into the beam path. Without the outer shell the beam tube temperature could not be actively regulated, but the type of wall considered for a passively isolated single thickness would have cost significantly more. This is the concept used for the construction of the AURORA laser 
device. It was constructed with 4 inch thick clad polyurethane BALLY panels on a concrete slab. The inner beam tube is 20 feet wide and ten feet tall over most of its length. The outer tube is $\mathbf{4 0}$ feet wide with an eave height of 12 feet over most of its length.

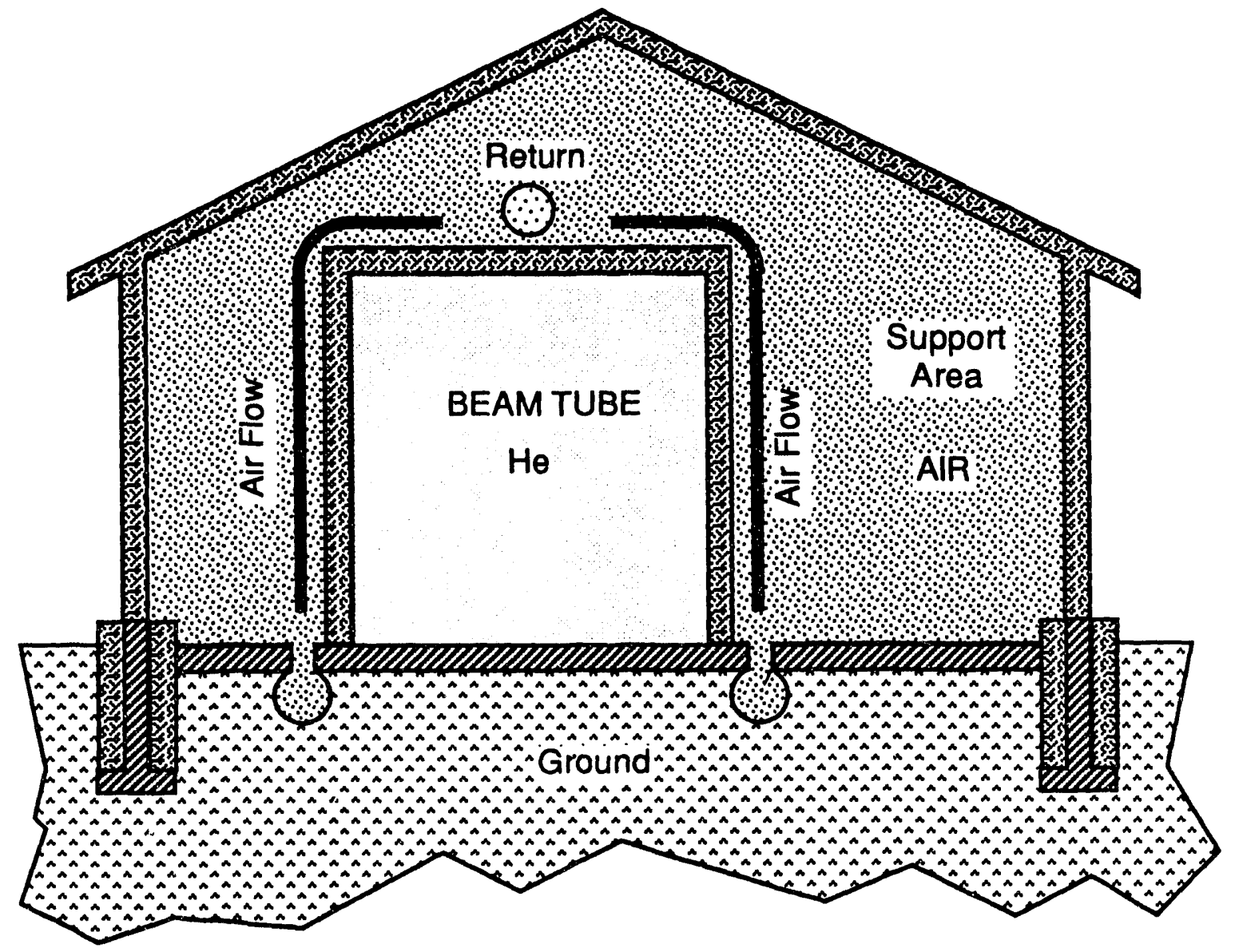

Figure 3.2-1. Baseline Concept

In order to develop alternative concepts that may be more cost-effective, the existing concept is investigated schematically, geometrically, and structurally. Schematics for a thermally stable beam tube could be developed into a number of topological configurations, as shown in figure 2, most of which are found in the AURORA device. As long as the requirement exists for active regulation of the beam tube temperature with a fluid media, there are no schematic alternatives to the tube (or tubes) within a tube. But, this schematic may be implemented with a variety of cross-sectional shapes in a variety of materials resulting in several new concepts. Also, if it can be shown that active regulation is not necessary, then there may be a feasible single tube schematic. 


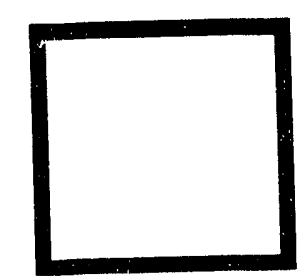

SINGLE TUBE

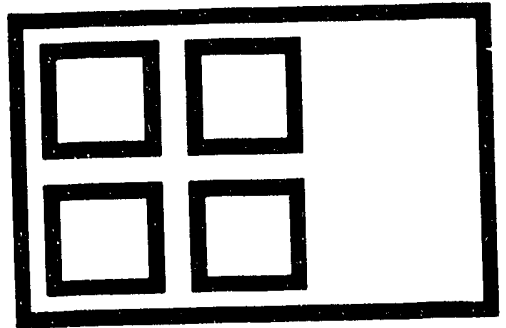

SEVERAL TUBES WITHIN A TUBE

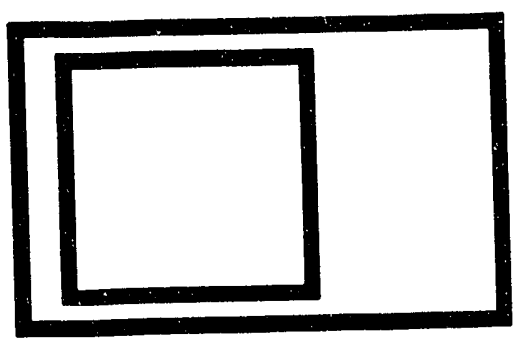

TUBE WITHIN A TUBE

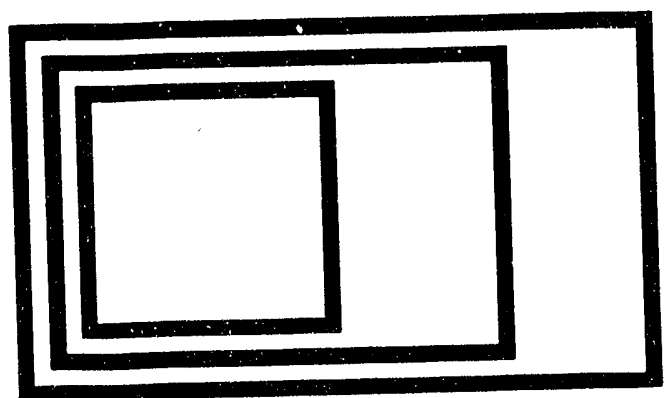

NESTED TUBES

\section{Figure 3.2-2. Beam Tube Schematics}

In the AURORA device, because the beam path lengths are short compared to the size of the optical devices, the beam tube is much wider than the actual beam over most of its length to accommodate the optics. Due to the constraints of the existing site, the beam path changes direction more than is desirable, resulting in a beam tube that is full of optics. In the optimum LMF design, there will be long stretches of empty beam tube and concentrated areas of optical devices. Therefore, it may be feasible to develop separate concepts for a simple beam tube and the beam tube with optics, as shown in figure 3 . 


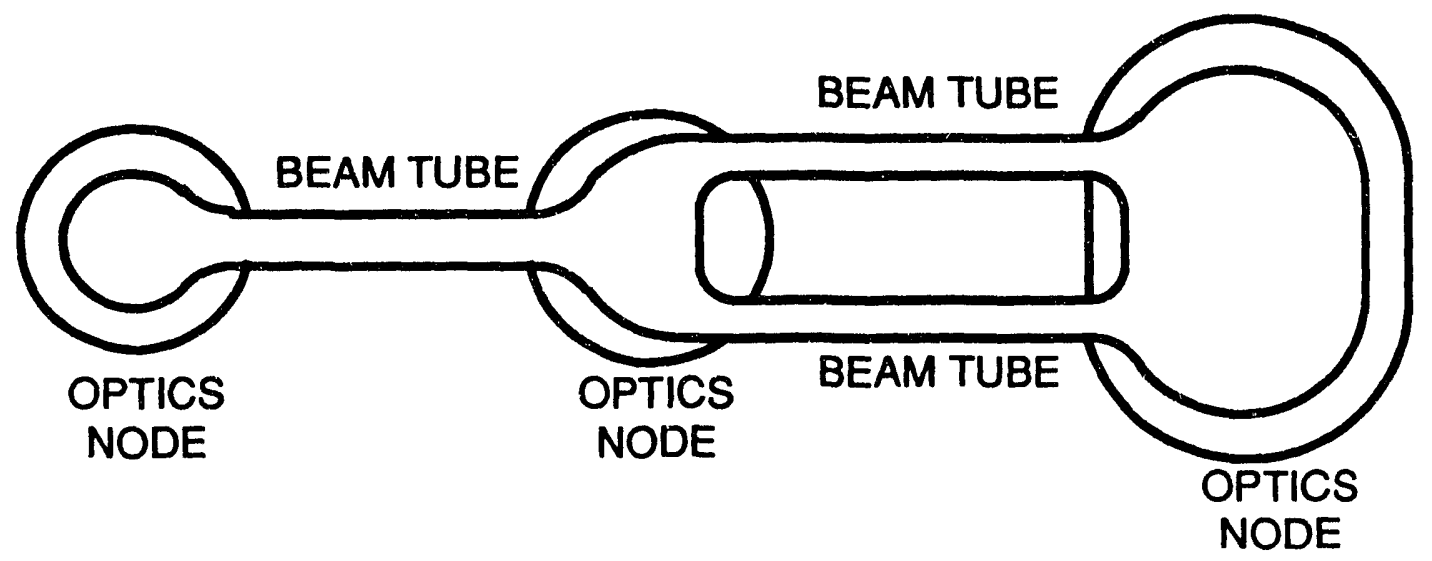

Figure 3.2-3. Support Areas Limited to Optics Nodes

For the laser optics to perform properly, the temperature gradients within the beam tube must be less than $.3^{\circ} \mathrm{C} /$ meter or $.8^{\circ} \mathrm{F} / \mathrm{ft}$.

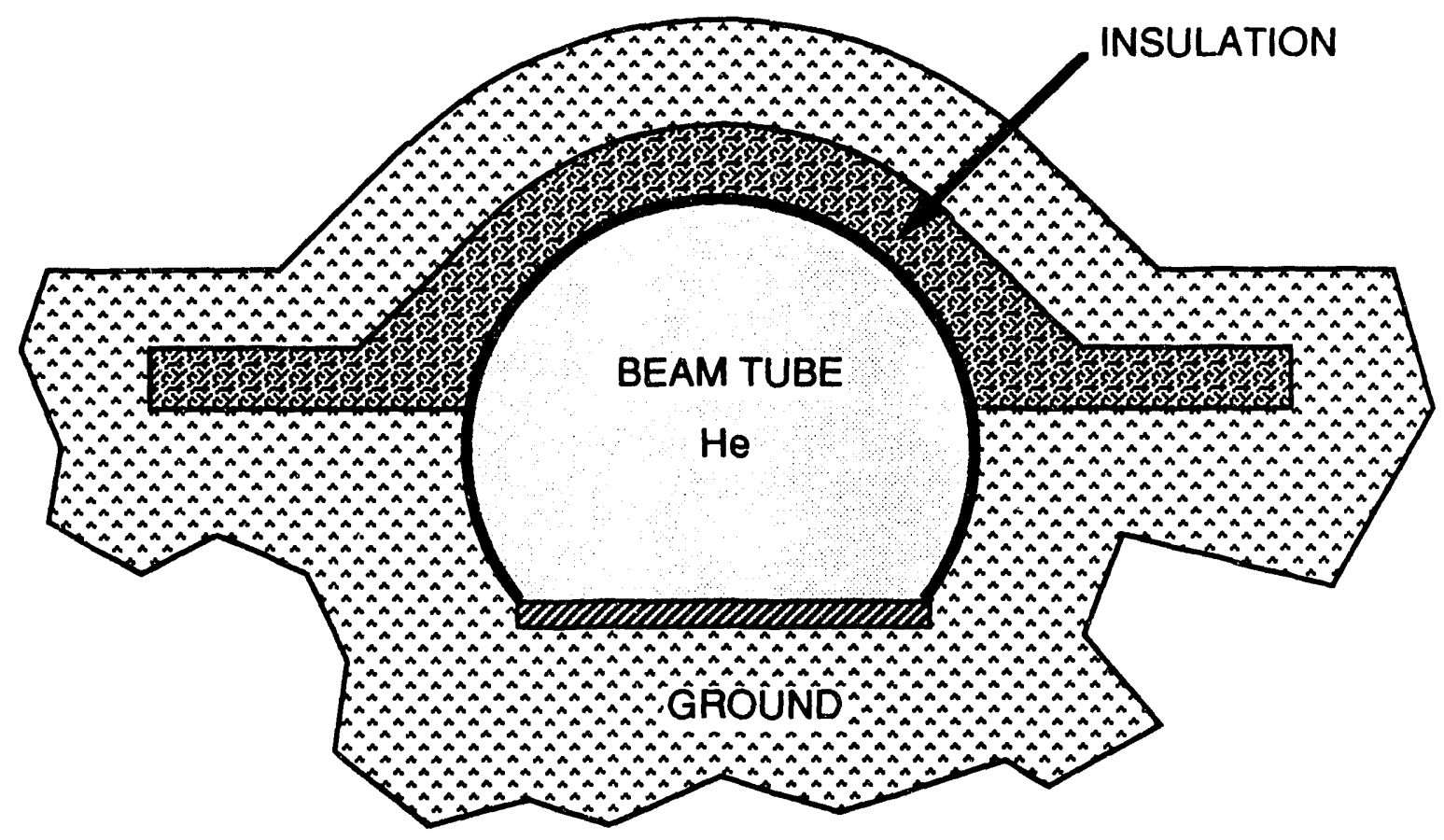

Figure 3.2-4. Earth Sheltered Concept 


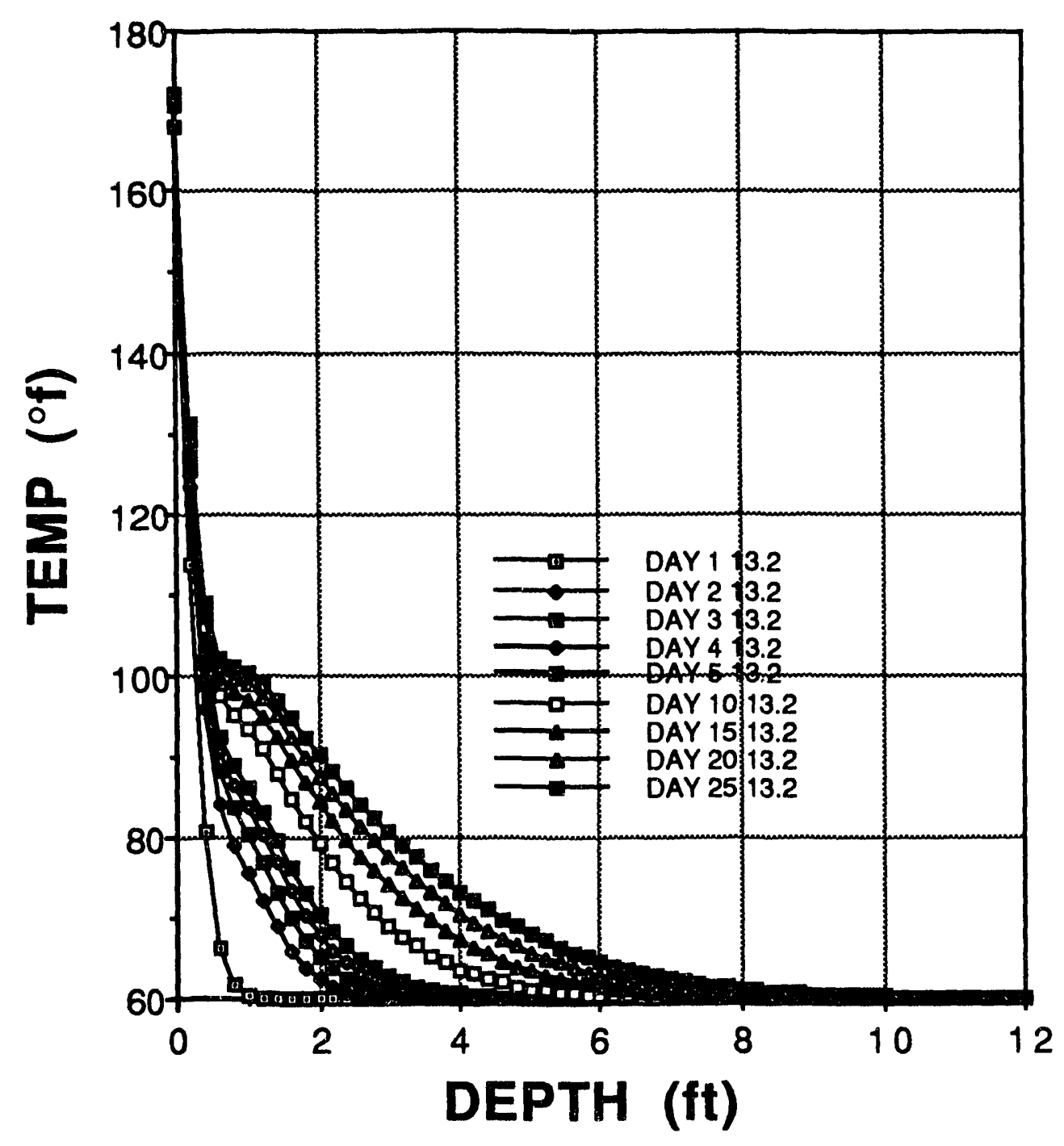




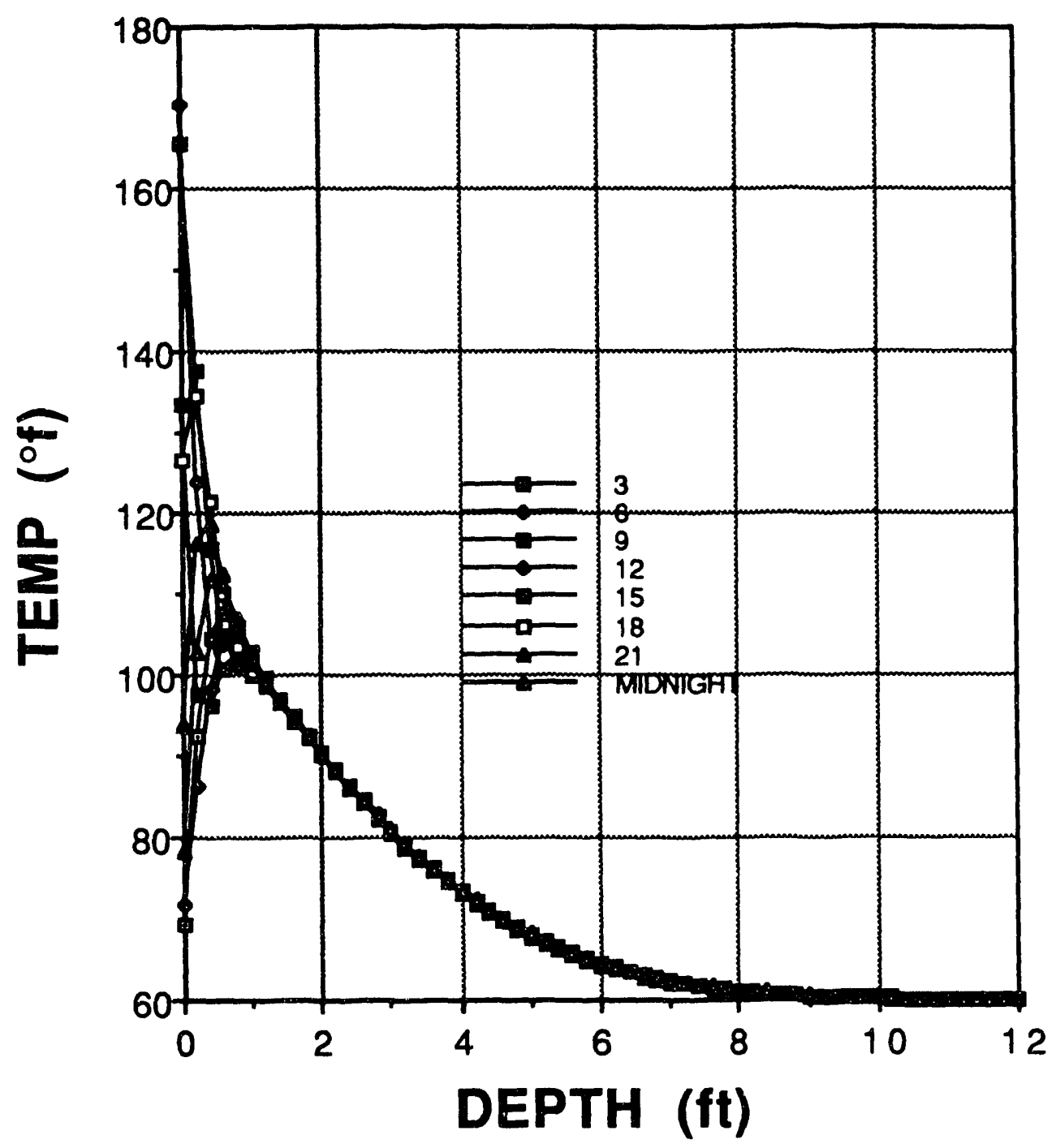




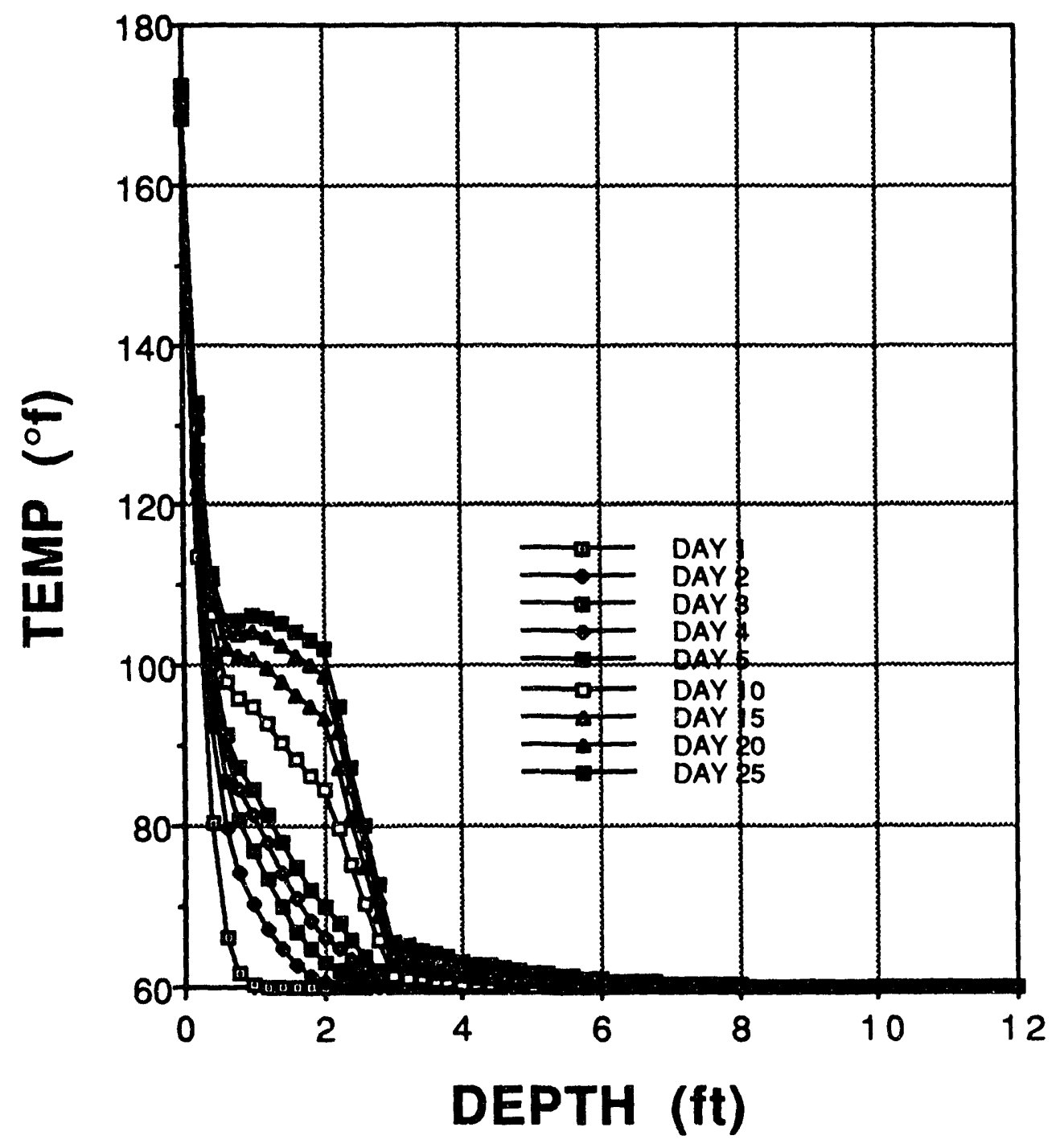




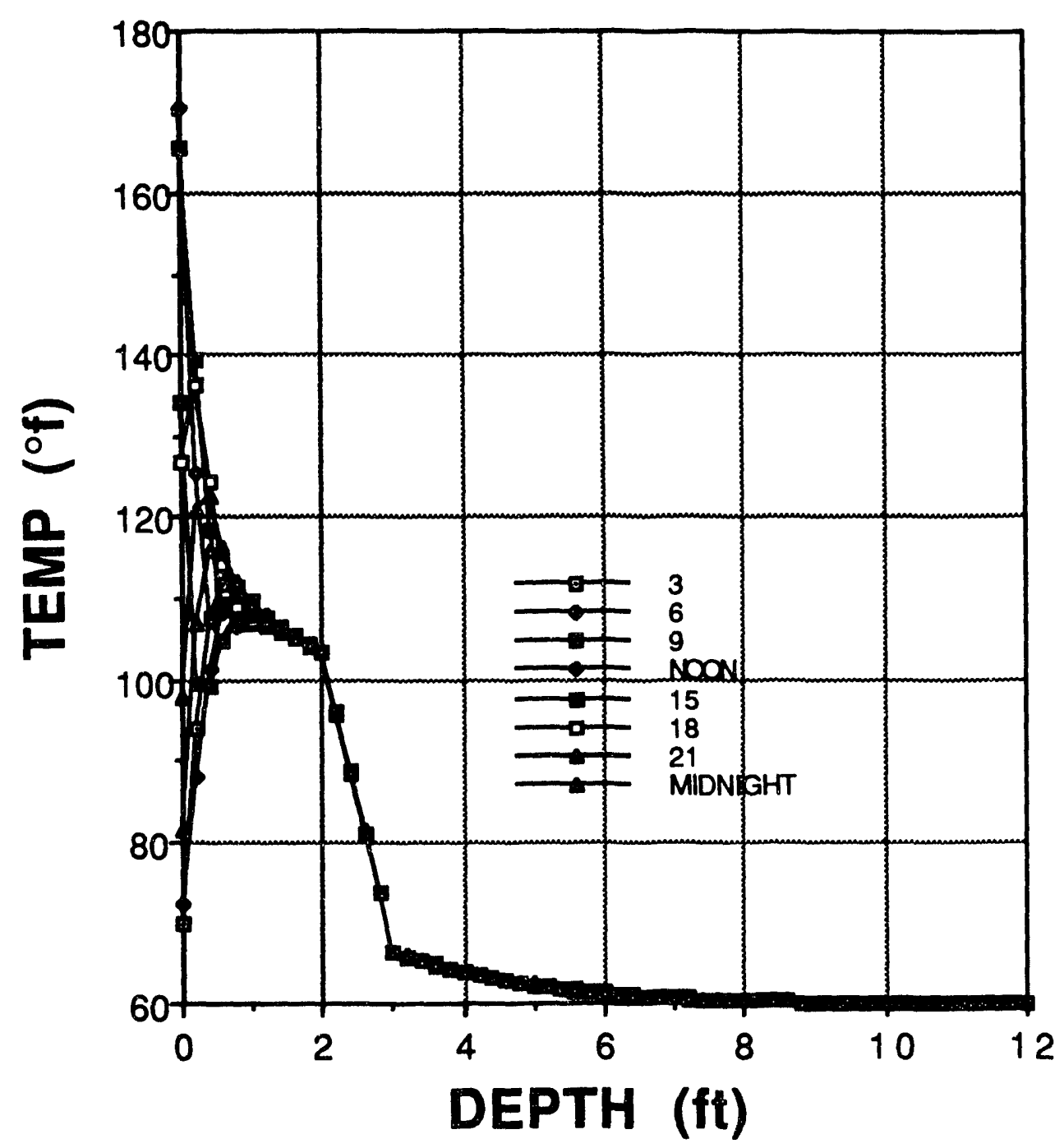

\subsection{COSTS}

For comparison, the above-ground BALLY type building and the earth-sheltered building were costed using available cost data., even though the BALLY type had already been given an estimate of $\$ 55 / \mathrm{sq} \mathrm{ft}$.

(1) BALLY TWO SHELL 
SLAB ON GRADE 4" THK NON INDUSTRIAL REINFORCED $\$ 2.21 / \mathrm{SQ}$ FT * 40 FT WIDE * $100 \mathrm{FT} \mathrm{LONG}=\$ 8,840.00$ TRENCH 4 FT DP 2 WIDE STRAIGHT SIDES

$\$ 2.23 / \mathrm{FT} * 2$ SIDES $100 \mathrm{FT}$ LONG $=$ $\$ 446.00$ STRIP FOOTING REINFORCED 2 FT WIDE 1 DP

$\$ 22.70 / \mathrm{FT} * 2$ SIDES $* 100 \mathrm{FT}$ LONG $=$ $\$ 4,540.00$ STEM WALLS 4 FT TALL 6" THK REINFORCED

$\$ 26.80 / \mathrm{FT} * 2$ SIDES $* 100 \mathrm{FT}$ LONG $=$ $\$ 5,360.00$ BEAM TUBE

WALL PANELS:

$\$ 8.00 / \mathrm{SQ} F \mathrm{FT} * 10 \mathrm{FT}$ TALL $* 100 \mathrm{FT}$ LONG $=$ $\$ 8,000.00$

WALL/CEILING:

$\$ 2.97 / \mathrm{FT} * 2$ SIDES * $100 \mathrm{FT}$ LONG $=\quad \$ 594.00$

CEILING:

$\$ 8.00 / \mathrm{SQ}$ FT $* 20 \mathrm{FT}$ WIDE $* 100 \mathrm{FT}$ LONG $=$

$\$ 16,000.00$

OUTER SHELL

WALL PANELS:

$\$ 8.00 / \mathrm{SQ}$ FT * 12 FT TALL * $100 \mathrm{FT} \mathrm{LONG}=$ $\$ 9,600.00$

WALL/CEILING:

$\$ 2.97 / \mathrm{FT} * 2$ SIDES * $100 \mathrm{FT} \mathrm{LONG}=\quad \$ 594.00$ CEILING:

$\$ 8.00 / \mathrm{SQ}$ FT $* 40 \mathrm{FT}$ WIDE $* 100 \mathrm{FT}$ LONG $=$

$\$ 32,000.00$

STEEL J\&G ON COL 40X40 BAY 51 PSF LOAD

$\$ 3.33 / \mathrm{SQ}$ FT $* 40 \mathrm{FT}$ WIDE $* 100 \mathrm{FT} \mathrm{LONG}=\$ 13,320.00$ HVAC

$\$ 1.25 / \mathrm{SQ}$ FT $* 40 \mathrm{FT}$ WIDE $* 100 \mathrm{FT} \mathrm{LONG}=\$ 5,000.00$ TOTAL 100 FT LONG TUNNEL $\$ 104,294.00$ 
One of the cost savings in the earth sheltered structure is that an HVAC system may not be required to maintain the temperature gradient if working conditions in a temperature slightly less than normal is acceptable.

(2) EARTH SHELTERED COST

TRENCH 10 FT WIDE X 20 FT DEEP $1 / 2$ TO 1 SLOPE

$$
\$ 52.00 / \mathrm{FT} * 100 \mathrm{FT} \mathrm{LONG}=\quad \$ 5,200.00
$$

CORRUGATED METAL PIPE 240" DIA 8 GA

$$
\$ 950.00 / \mathrm{FT} * 100 \mathrm{FT} \mathrm{LONG}=\quad \$ 95,000.00
$$

TOTAL 100 FT LONG TUNNEL $\$ 100,200.00$ 
BDM INTERNATIONAL, INC.

\section{APPENDIX}

OPTICS TECHNOLOGY SURVEY 


\section{UV LASER OPTICS FABRICATION \\ TECHNOLOGY AND COST SURVEY}

This survey will provide us with the information to recommend cost reduction techniques for the manufacture of optical components for the LANL KrF Laser-Driven LMF facility. Do not let the size of this survey scare you. You will probably need to fill out only 3 pages out of the nine total. Please be specific in your response to the questions - the more information you provide, the more helpful it will be to us. The information provided here will be used to establish baselines and boundaries. We are using your input to identify and quantify different technologies - not companies. You are not in competiton with other companies. Your responses will not be used as the basis of any contract awards now, or in the future.

1.a Company Narite

1.b Department

1.c Your Name, Phone Number

1.d Today's Date

2.a Check all materials that apply in your process. Specify any others that have not been listed that you feel will have a significant cost impact. Check as many as apply.

$\begin{array}{ll}\square & \text { Fused Silica } \\ \square & \text { Borosilicates } \\ \square & \text { Zerodur }^{\mathrm{TM}} \\ \square & \text { ULE }^{\mathrm{TM}} \\ \square & \text { Epoxy }\end{array}$

2.b Provide a sketch of a block diagram of your company's process. Provide some explaination of each step of the process. Include all testing and quality assurance steps that may be part of the process. Show any iterative loops and specify the approximate or average numb. , of iterations. Please be as specific as possible. Use the next page plus additional pages if needed, or, utilized printed materials you may already have. Specity the elapsed clock time required for each step of the process and specify whether the step can be conducted on more than one item at a time (example: Four Mirror blanks can be polished on one machine at one time) 
Example Process:

For example, the following type of information may be entered for solid mirror blank fabrication. Hand sketches are OK.

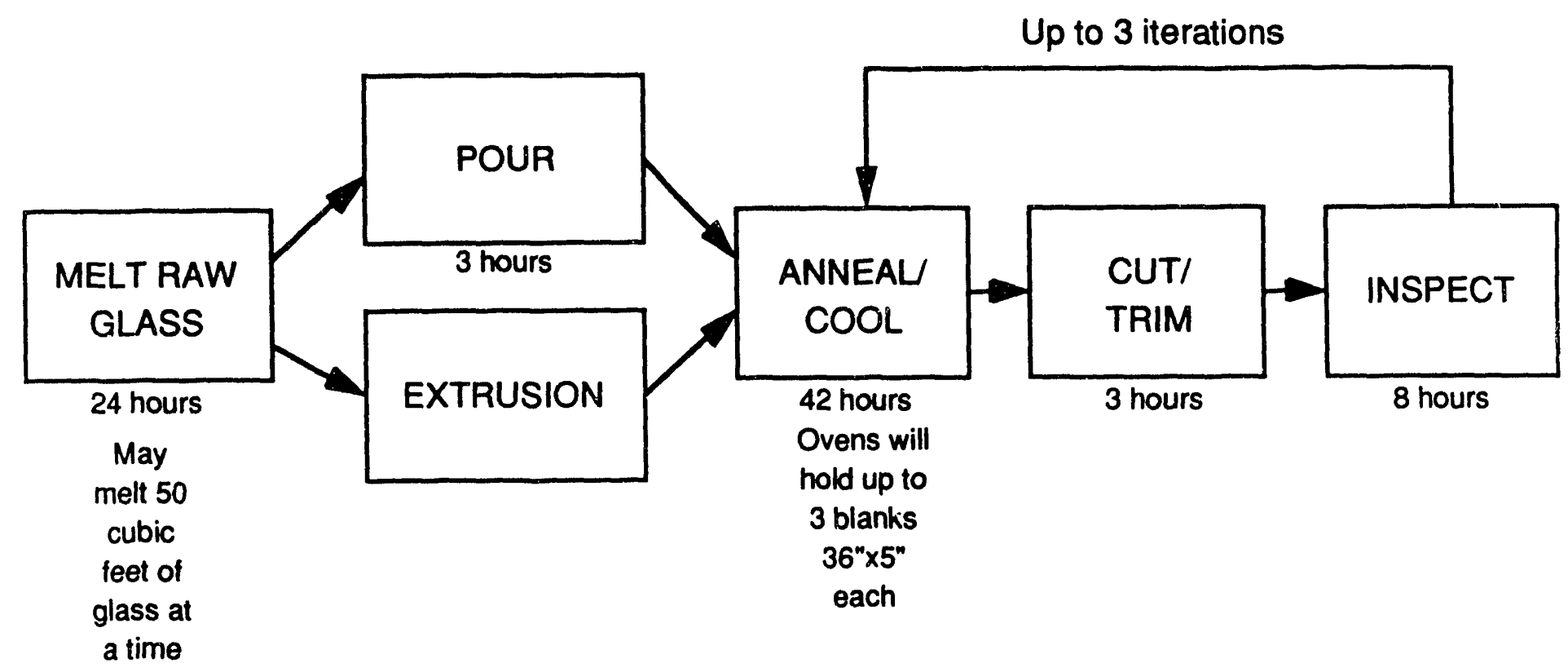


Your Process: 


\section{GLASS MAKING}

2.a.1.1 What is the availability of each of the raw materials (Rank: $0=$ Not Available, 5=Always available)

2.a.1.2 For each type of glass your company manufactures, list it's approximate mass characteristics. Example: Fused Silica is approximately $2.116 \mathrm{~g} / \mathrm{cm} 3$. Use $\mathrm{g} / \mathrm{cm} 3, \mathrm{lbs} / \mathrm{ft} 3$, Ibs/in3, $\mathrm{kg} / \mathrm{m3}$, etc.

2.a.1.3 In what units is your glass sold in? Examples, pounds, cubic feet, cubic meters, 4 foot by 8 foot by 1 inch sheets, etc.

2.a.1.4 What is the cost for one of the above units?

2.a.1.5 What is the unit cost for buying quantities of the above units?

For example, if we buy one, cost is $\$ 1.00$, but if we buy $2-10$, the cost is $95 \varnothing$ each Use the table below

\begin{tabular}{|c|l|}
\hline UNIT QUANTITY & $\begin{array}{l}\text { COST OF } \\
\text { EACH UNIT }\end{array}$ \\
\hline 1 & \\
\hline & \\
\hline & \\
\hline & \\
\hline & \\
\hline & \\
\hline & \\
\hline
\end{tabular}




\section{MIRROR BLANKS \\ AND WINDOWS}

3.a What do you produce?

$\square$ Solid blanks (go to question 2.a.3)

$\square$ Lightweight blanks

$\square$ Windows (go to question 2.a.3)

3.b What type of lightweight mirror do you produce?
- Hexagonal Core Elements/Honeycomb
$\square$ Triangular Core Elements
$\square$ Square Core Elements
$\square$ Double Arch

3.c Blank Physical Characteristics - list the thickness and weight of your blanks or windows with the following characteristics:

- Square $26^{\prime \prime}$ by $26^{\prime \prime}$

- Circle $37^{n}$ diameter

3.d What is the unit cost for buying quantities of the windows or mirror blanks? Use the table below.

\begin{tabular}{|c|c|c|c|c|c|c|}
\hline \multirow{3}{*}{ UNIT QUANTITY } & \multicolumn{6}{|c|}{ COST OF EACH UNIT } \\
\hline & \multicolumn{3}{|c|}{$26^{n} \times 26^{n}$ SQUARE } & \multicolumn{3}{|c|}{$37^{\prime \prime}$ ROUND } \\
\hline & PLANO & $\begin{array}{c}\text { SPHERICAL } \\
\text { CONCAVE } \\
\end{array}$ & $\begin{array}{l}\text { SPHERICAL } \\
\text { CONVEX } \\
\end{array}$ & PLANO & $\begin{array}{l}\text { SPHERICAL } \\
\text { CONCAVE }\end{array}$ & $\begin{array}{l}\text { SPHERICAL } \\
\text { CONVEX }\end{array}$ \\
\hline 1 & & & & & & \\
\hline & & & & & & \\
\hline & & & & & & \\
\hline & & & & & & \\
\hline & & & & & & \\
\hline & & & & & & \\
\hline & & & & & & \\
\hline
\end{tabular}

3.e Comments 


\section{FINISHING/POLISHING}

Our requirement is to finish and polish approximately 8000 mirrors with $2 / 3$ of those being weakly powered spherical and the remaining $1 / 3$ being flat. They must have a surface error of $\lambda / 10$ or and $20 \AA$ RMS.

3.a Identify each piece of equipment used in finishing or polishing. Identify the approximate price of each piece of equipment, the quantity needed to finish the mirrors in five years, and the number of mirrors (flat and curved, round and square) that the equipment can process concurrently.

3.b Using the table below, indicate the cost (including quantity discounts) of polishing the following pieces to a $\lambda / 10$ surface:

\begin{tabular}{|c|c|c|c|c|c|c|}
\hline \multirow{3}{*}{ UNIT QUANTITY } & \multicolumn{5}{|c|}{ COST OF EACH UNIT } \\
\cline { 2 - 7 } & PLANO & $\begin{array}{c}\text { SPHERICAL } \\
\text { CONCAVE }\end{array}$ & $\begin{array}{c}\text { SPHERICAL } \\
\text { CONVEX }\end{array}$ & PLANO & $\begin{array}{c}\text { SPHEAICAL } \\
\text { CONCAVE }\end{array}$ & $\begin{array}{c}\text { SPHERICAL } \\
\text { CONVEX }\end{array}$ \\
\hline & & & & & & \\
\hline & & & & & & \\
\hline & & & & & & \\
\hline & & & & & & \\
\hline & & & & & & \\
\hline & & & & & & \\
\hline & & & & & & \\
\hline
\end{tabular}

3.c Comments 


\section{ION FIGURING}

Our requirement is to finish and polish approximately 8000 mirrors with $2 / 3$ of those being weakly powered spherical and the remaining $1 / 3$ being flat. They must have a surface error of $\lambda / 10$ or and $20 \AA$ RMS.

3.a Identify each piece of ion figuring equipment used in figuring the mirrors. Identify the approximate price of each piece of equipment and the number of mirrors (flat and curved, round and square) that the equipment can process concurrently.

3.b Using the table below, indicate the cost (including quantity discounts) of finishing the following pieces to a $\lambda / 10$ surface:

\begin{tabular}{|c|c|c|c|c|c|c|}
\hline \multirow{3}{*}{ UNIT QUANTITY } & \multicolumn{5}{|c|}{ COST OF EACH UNIT } \\
\cline { 2 - 7 } & PLANO & $\begin{array}{c}\text { SPHERICAL } \\
\text { CONCAVE }\end{array}$ & $\begin{array}{c}\text { SPHERICAL } \\
\text { CONVEX }\end{array}$ & PLANO & $\begin{array}{c}\text { SPHERICAL } \\
\text { CONCAVE }\end{array}$ & $\begin{array}{c}\text { SPHERICAL } \\
\text { CONVEX }\end{array}$ \\
\hline & & & & & & \\
\hline & & & & & & \\
\hline & & & & & & \\
\hline & & & & & & \\
\hline & & & & & & \\
\hline & & & & & & \\
\hline & & & & & & \\
\hline
\end{tabular}

3.c Comments 


\section{COATING}

Our requirement is to finish and polish approximately 8000 mirrors with $2 / 3$ of those being weakly powered spherical and the remaining $1 / 3$ being flat. Coated surface characteristics are Max R at 248nm with $5 \mathrm{~J} / \mathrm{sq} \mathrm{cm}$ damage threshold.

3.a What type of coating is employed at your facility?

$\square$ Ion Deposition

Metal Vapor Deposition

$\square$ Other (Specify

3.b Identify each piece of equipment used in coating the mirrors. Identify the approximate price of each piece of equipment and the number of mirrors (flat and curved, round and square) that the equipment can process concurrently.

3.c Using the table below, indicate the cost (including quantity discounts) of coating the following pieces:

\begin{tabular}{|c|c|c|c|c|c|c|}
\hline \multirow{3}{*}{ UNIT QUANTITY } & \multicolumn{6}{|c|}{ COST OF EACH UNIT } \\
\hline & \multicolumn{3}{|c|}{$26^{\prime \prime} \times 26^{\prime \prime}$ SQUARE } & \multicolumn{3}{|c|}{$37^{n}$ ROUND } \\
\hline & PLANO & $\begin{array}{l}\text { SPHERICAL } \\
\text { CONCAVE }\end{array}$ & $\begin{array}{c}\text { SPHERICAL } \\
\text { CONVEX } \\
\end{array}$ & PLANO & \begin{tabular}{|l|} 
SPHERICAL \\
CONCAVE \\
\end{tabular} & $\begin{array}{c}\text { SPHERICAL } \\
\text { CONVEX } \\
\end{array}$ \\
\hline 1 & & & & & & \\
\hline & & & & & & \\
\hline & & & & & & \\
\hline & & & & & & \\
\hline & & & & & & \\
\hline & & & & & & \\
\hline & & & & & & \\
\hline
\end{tabular}

3.d Comments 


\section{MIRROR/WINDOW MOUNTS}

Our requirement is to provide 2-axis digitally micro-positioning mounts for approximately 8000 mirrors with $2 / 3$ of those being weakly powered spherical and the remaining $1 / 3$ being flat. There must be no interference with the clear aperture of these mirrors.

3.a Provide a drawing and description of the type of mounts your company can provide. Brocures, sales literature, and/or technical specifications are acceptable provided they include drawings and/or photographs of the mounts. Include the positioning increments.

3.b Identify each piece of equipment used in constructing the mirror mounts and attaching the mirrors to the mounts. Identify the approximate price of each piece of equipment.

3.c Using the table below, indicate the cost (including quantity discounts) of providing mounts for and mounting the following mirrors:

\begin{tabular}{|c|c|c|}
\hline \multirow{2}{*}{ UNIT QUANTITY } & \multicolumn{2}{|c|}{ COST OF EACH UNIT } \\
\hline & $26^{\prime \prime} \times 26^{\prime \prime}$ SQUARE & $37^{\prime \prime}$ ROUND \\
\hline 1 & & \\
\hline & & \\
\hline & & \\
\hline & & \\
\hline & & \\
\hline & & \\
\hline & & \\
\hline
\end{tabular}

3.d Comments 


\section{REPLICATION}

Our requirement is to produce approximately 8000 finished mirrors with $2 / 3$ of those being weakly powered spherical and the remaining $1 / 3$ being flat. They must have a surface error of $\lambda / 10$ or and $20 \AA$ RMS.

3.a Identify each piece of replication $\epsilon$ quipment used in making the mirrors and mandrels. Identify the approximate price of each piece of equipment and the number of mirrors (flat and curved, round and square) that the equipment can process concurrently.

3.b Using the table below, indicate the cost (including quantity discounts) of the following completed replicated mirrors:

\begin{tabular}{|c|c|c|c|c|c|c|}
\hline \multirow{3}{*}{ UNIT QUANTITY } & \multicolumn{5}{|c|}{ COST OF EACH UNIT } \\
\cline { 2 - 7 } & PLANO & $\begin{array}{c}\text { SPHERICAL } \\
\text { CONCAVE }\end{array}$ & $\begin{array}{c}\text { SPHERICAL } \\
\text { CONVEX }\end{array}$ & PLANO & $\begin{array}{c}\text { SPHERICAL } \\
\text { CONCAVE }\end{array}$ & $\begin{array}{c}\text { SPHERICAL } \\
\text { CONVEX }\end{array}$ \\
\hline & & & & & & \\
\hline & & & & & & \\
\hline & & & & & & \\
\hline & & & & & & \\
\hline & & & & & & \\
\hline & & & & & & \\
\hline
\end{tabular}

3.c Comments 

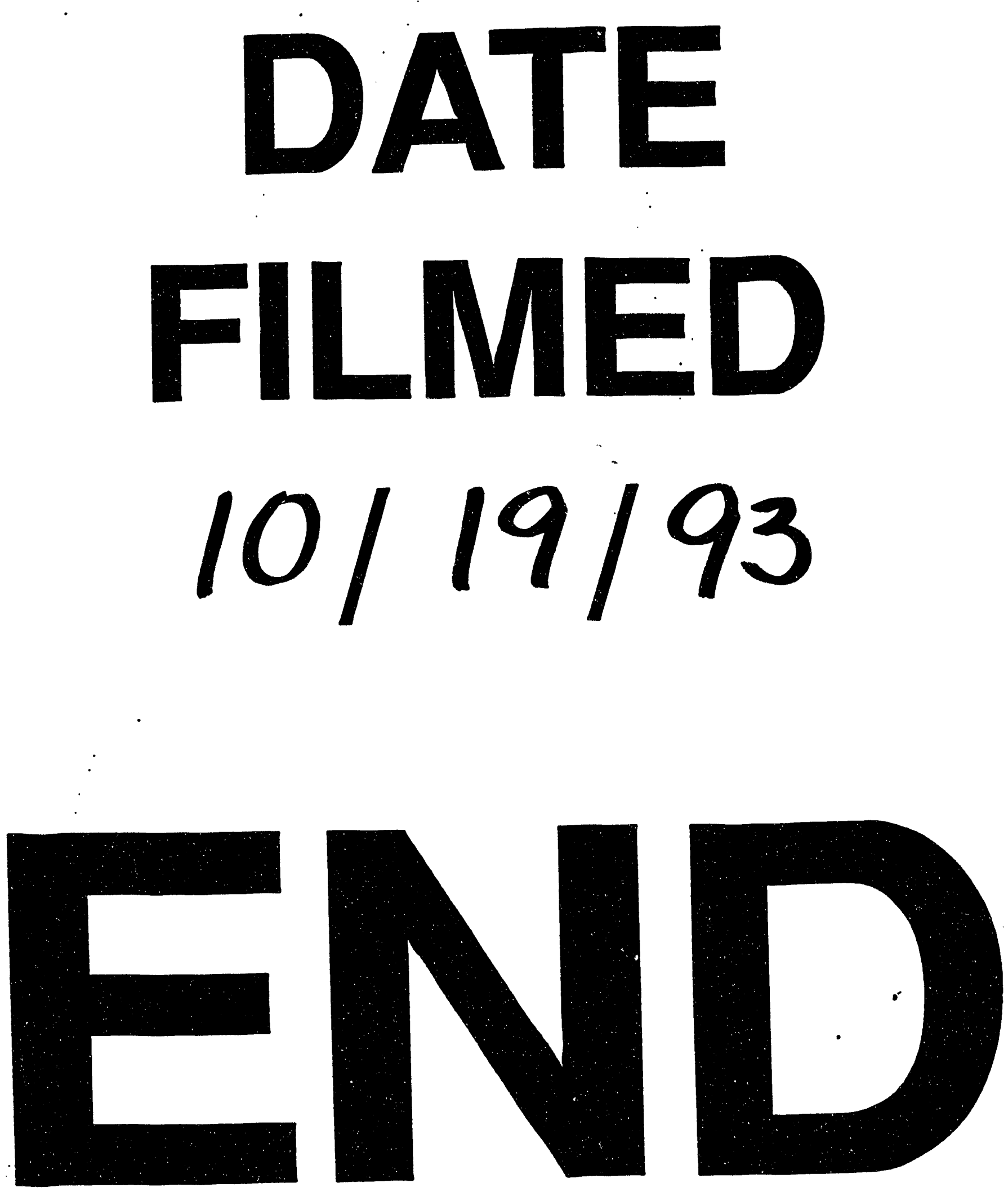
